\title{
Brazilian Society of Hepatology updated recommendations for diagnosis and treatment of hepatocellular carcinoma
}

\author{
Aline Lopes CHAGAS ${ }^{1,2}$, Angelo Alves de MATTOS ${ }^{3}$, Flair José CARRILH0 ${ }^{1,2}$, Paulo Lisboa BITTENCOURT4 \\ and Members of the Panel of the 2nd Consensus of the Brazilian Society of Hepatology on the \\ Diagnosis and Management of Hepatocellular Carcinoma *
}

Received: 13 December 2019 Accepted: 19 December 2019

\begin{abstract}
Hepatocellular carcinoma (HCC) is one of the leading causes of cancer-related mortality worldwide. The Brazilian Society of Hepatology (SBH) published in 2015 its first recommendations about the management of HCC. Since then, new data have emerged in the literature, prompting the governing board of SBH to sponsor a single-topic meeting in August 2018 in São Paulo. All the invited experts were asked to make a systematic review of the literature reviewing the management of HCC in subjects with cirrhosis. After the meeting, all panelists gathered together for the discussion of the topics and the elaboration of updated recommendations. The text was subsequently submitted for suggestions and approval of all members of the Brazilian Society of Hepatology through its homepage. The present manuscript is the final version of the reviewed manuscript containing the recommendations of $\mathrm{SBH}$.
\end{abstract}

HEADINGS - Hepatocelullar carcinoma, diagnosis. Hepatocelullar carcinoma, therapy. Liver neoplasms. Medical societies. Brazil.

\section{INTRODUCTION}

The Brazilian Society of Hepatology (SBH) published in 2015 the recommendations for the diagnosis and treatment of hepatocellular carcinoma $(\mathrm{HCC})^{(1)}$. Since then, new scientific evidence has been published in the literature, with great impact on current HCC management. In order to update the recommendations on the diagnosis and treatment of HCC, the SBH held on August 16, 2018 a single-topic meeting on the subject with the support of the Brazilian Society of Clinical Oncology (SBOC), Brazilian Society of Interventional Radiology and Endovascular Surgery (SOBRICE), Brazilian College of Radiology (CBR), Brazilian Association of Organ Transplantation (ABTO), International Hepato-Pancreato-Biliary Association (IHPBA) and the Brazilian Society of Pathology (SBP).

The purpose of this document was to assist healthcare professionals, policy-makers and planners in Brazil in decision-making regarding the management of patients with HCC. It is important to note, however, that the recommendations presented in this manuscript, based on currently available evidence, were written to guide clinical practice in circumstances where all resources and therapies are available. These recommendations should, therefore, be adapted according to local regulations, expertise, infrastructure and treatment availability, with the primary aim of improving the care and quality of life of patients with HCC.

The SBH liver tumor interest group chose an organizing committee that, together with the other participating societies, designated 29 researchers to be moderators or speakers on HCC management issues. All topics were covered according to the degree of available scientific evidence. The recommendations were prepared in a face-to-face meeting after extensive discussion with the organizing committee members, moderators, and participants of the single-topic meeting. The organizing committee was responsible for drafting a preliminary document, which was later submitted to SBH members via homepage for suggestions before writing the final version of the present manuscript.

The classification of evidence levels and recommendations was based on a modification of the GRADE ${ }^{(2)}$ system, as described in TABLE 1.

\footnotetext{
Declared conflict of interest of all authors: none

Disclosure of funding: no funding received

* Denise Cerqueira Paranaguá Vezozzo ${ }^{1}$, Natally Horvat ${ }^{1,5}$ Manoel de Souza Rocha ${ }^{1}$ Venâncio Avancini Ferreira Alves 1,2 Gabriela Perdomo Coral ${ }^{3}$, Mario Reis Alvares-da-Silva ${ }^{6}$, Fabio Marinho do Rego Barros ${ }^{7}$, Marcos Roberto Menezes ${ }^{1,2,5}$, Lucas Moretti Monsignore, Fabricio Ferreira Coelho ${ }^{1}$, Renato Ferreira da Silva ${ }^{9}$, Rita de Cássia Martins Alves Silva ${ }^{9}$, Ilka de Fatima Santana Ferreira Boin ${ }^{10}$, Luiz Augusto Carneiro d`Albuquerque ${ }^{1}$, José Huygens Parente Garcia ${ }^{11}$, Guilherme Eduardo Gonçalves Felga ${ }^{12}$, Airton Mota Moreira ${ }^{1,2}$, Maria Ignez Freitas Melro Braghiroli ${ }^{2}$, Paulo Marcelo Gehm Hoff², Vivianne Barretto de Mello ${ }^{13}$, Mariana Fonseca Dottori ${ }^{14}$, Tiago Pugliese Branco ${ }^{2}$, Leonardo de Lucca Schiavon ${ }^{15}$, Thaisa de Fátima Almeida Costa ${ }^{2}$

'Universidade de São Paulo, Faculdade de Medicina, Hospital das Clínicas, São Paulo, SP, Brasil. ${ }^{2}$ Universidade de São Paulo, Instituto do Câncer do Estado de São Paulo, São Paulo, SP, Brasil. ${ }^{3}$ Universidade Federal de Ciências da Saúde de Porto Alegre e Irmandade da Santa Casa de Misericórdia de Porto Alegre, Porto Alegre, RS, Brasil. ${ }^{4}$ Hospital Português, Salvador, BA, Brasil. ${ }^{5}$ Hospital Sírio-Libanês, São Paulo, SP, Brasil. ${ }^{6}$ Universidade Federal do Rio Grande do Sul, Hospital de Clínicas de Porto Alegre, Porto Alegre, RS, Brasil. ${ }^{7}$ Hospital Português de Beneficência, Recife, PE, Brasil. ${ }^{8}$ Universidade de São Paulo, Hospital das Clínicas da Faculdade de Medicina de Ribeirão Preto, São Paulo, SP, Brasil. ${ }^{9}$ Faculdade de Medicina de São José do Rio Preto (FAMERP) e Hospital de Base de São José do Rio Preto (FUNFARME) São José do Rio Preto, SP Brasil. 10 Universidade Estadual de Campinas, Faculdade de Ciências Médicas (FCM-Unicamp), Campinas, SP, Brasil. ${ }^{11}$ Universidade Federal do Ceará, Fortaleza, CE, Brasil. ${ }^{12}$ Hospital Israelita Albert Einstein, São Paulo, SP, Brasil. ${ }^{13}$ Universidade Federal da Bahia, Salvador, BA, Brasil. ${ }^{14}$ Hospital Federal dos Servidores do Estado, Rio de Janeiro, RJ, Brasil. ${ }^{15}$ Universidade Federal de Santa Catarina, Florianópolis, SC, Brasil.

Corresponding author: Aline Lopes Chagas, MD. E-mail: alinelchagas@gmail.com
} 
TABLE 1 . The classification of evidence levels and recommendations according to the modified GRADE system ${ }^{(2)}$.

\begin{tabular}{lll}
\hline Level of Evidence & & Degree of confidence in the evidence \\
\hline High & $\begin{array}{l}\text { Data from meta-analyzes or systematic reviews or } \\
\text { various high quality randomized controlled trials. } \\
\text { Data from a single randomized controlled trial } \\
\text { or from multiple nonrandomized studies. } \\
\text { Data from small studies, retrospective, } \\
\text { observational studies or case series }\end{array}$ & $\begin{array}{l}\text { Future research is unlikely to change the proposal } \\
\text { prested }\end{array}$ \\
Fow & $\begin{array}{l}\text { Future research may have impact on the proposal } \\
\text { presented. }\end{array}$ & $\begin{array}{l}\text { Future research is likely to have a significant impact on } \\
\text { the proposal presented. }\end{array}$ \\
\hline Grade of Recommendation & & Writing associated with degree of recommendation \\
\hline Strong & "must", "strongly indicated" or "SBH recommends" \\
Weak & "can" or "SBH suggests" \\
\hline
\end{tabular}

\section{EPIDEMIOLOGY}

Liver cancer is the 6 th cause of cancer and 4 rd cause of cancerrelated deaths in the world. HCC is responsible for $75 \%-85 \%$ of cases of primary liver neoplasms. The annual estimated global incidence is 500,000 to $1,000,000$ cases, leading to more than 700,000 deaths per year ${ }^{(3)}$. The relevance of HCC and its underlying etiologies increased significantly from 1990 to 2015 at the global, national, and regional levels ${ }^{(4,5)}$. In Brazil, analyzing the burden of liver disease, liver tumors was the eighth cause of death in disease ranking, considering 850,000 hospitalizations and 300,000 deaths, and it was one of the leading causes of death among all liver diseases $^{(6)}$. Nowadays, HCC is the most frequent complication and the leading cause of death in patients with compensated cirrhosis. The vast majority of HCC cases are associated with cirrhosis. Hepatitis B (HBV) along with hepatitis $\mathrm{C}$ virus (HCV) infections is responsible for over $80 \%$ of HCC cases worldwide ${ }^{(4,5)}$.

From an epidemiological point of view, HCC is characterized by a wide geographical variability, with a highly heterogeneous distribution, probably related to etiological factors such as the prevalence of $\mathrm{HBV}$ and $\mathrm{HCV}$ infection and exposure to aflatoxin B. More than $80 \%$ of cases occur in Sub-Saharan Africa and East Asia, which are considered high-incidence $\operatorname{areas}^{(7)}$. Recent studies in Europe and the United States of America (USA) have shown an increase in HCC-related mortality, while cirrhosis-related mortality rates have declined or remained stable. In USA, HCC is the highest growing cancer-related cause of death, with an $80 \%$ increase in annual incidence over the past two decades ${ }^{(7,8)}$.

Brazil is considered a country with an intermediate incidence of $\mathrm{HCC}^{(5)}$. A study conducted at the University of São Paulo showed an annual incidence of $3.5 \%$ in cirrhotic patients ${ }^{(9)}$. In 2009, a national hepatologists survey of 1,405 patients diagnosed with $\mathrm{HCC}$ from 29 centers showed that cirrhosis was present in $98 \%$ of cases, and chronic HCV infection was the most common etiology (54\%), followed by HBV $(16 \%)$ and alcohol $(14 \%)^{(10)}$.

\section{RISK FACTORS}

Cirrhosis of any etiology is the major risk factor for the development of HCC, particularly when associated with HCV and HBV, exposure to aflatoxins, alcohol abuse, diabetes, obesity, non-alcoholic fatty liver disease (NAFLD) and hereditary hemochromatosis $(\mathrm{HH})$. Older age, male gender, the severity of cirrhosis, and sustained inflammatory activity are also predictors of HCC, regardless of the etiology of cirrhosis. Considering viral etiology, the co-infection of HBV and HCV or HBV and hepatitis D virus increases the risk of HCC. Alcohol abuse also increases such risk ${ }^{(11)}$.
In patients with $\mathrm{HBV}$, the risk of developing $\mathrm{HCC}$ increases with the progression of hepatitis, high rates of viral replication (HBV DNA $>10,000$ copies or 2,000 UI/mL), and genotypes $\mathrm{B}$ or $\mathrm{C}^{(12)}$.

In hepatitis $\mathrm{C}$, sustained virological response (SVR) to antiviral therapy significantly decreases the risk of HCC but does not eliminate it, and these patients may develop a tumor even after SVR ${ }^{(13)}$.

Aflatoxins $\mathrm{B}$ are carcinogenic in humans, and their presence in the diet correlates with the incidence of $\mathrm{HCC}^{(14)}$. Molecular events associated with HCC are related to genetic changes and mutations (such as a mutation in the p53 gene) triggered by exposure to this toxin. The 249Ser TP53 mutation was detected in $28 \%$ of HCC samples in Brazil, considered to be a high prevalence rate ${ }^{(15)}$.

Prolonged and abusive alcohol intake is an established risk factor for HCC, either independently or associated with $\mathrm{HCV}$ and HBV infection. Among chronic alcoholics, the risk of HCC increases linearly with daily intake exceeding $60 \mathrm{~g}$ of alcohol, and it doubles in the presence of HCV infection ${ }^{(16)}$.

Diabetes, overweight, and obesity are also associated with increased risk of $\mathrm{HCC}^{(17,18)}$. Non-alcoholic steatohepatitis (NASH), particularly with advanced fibrosis, is an important risk factor for the development of $\mathrm{HCC}^{(19-21)}$.

Finally, patients with $\mathrm{HH}$ are also at increased risk of developing HCC, particularly among those with cirrhosis ${ }^{(22)}$.

\section{PREVENTION}

One of the primary forms of HCC prevention is universal HBV vaccination. Studies in HBV-endemic countries such as Taiwan have shown that universal immunization has led to a reduction in the incidence of hepatitis B-related HCC in children and adults ${ }^{(23)}$. The World Health Organization (WHO) recommends hepatitis B vaccination for all newborns and all high-risk groups ${ }^{(24)}$.

Regarding secondary prevention of HCC, studies have already demonstrated the beneficial effects of antiviral therapies for hepatitis $\mathrm{B}$ and $\mathrm{C}$ in reducing the incidence of $\mathrm{HCC}$. In the case of hepatitis $\mathrm{B}$, observational studies using interferon (IFN) and both randomized and case-control studies using nucleoside analogues, such as entecavir and tenofovir, have demonstrated the beneficial effect of these treatments in reducing HCC incidence ${ }^{(25-28)}$.

In hepatitis $\mathrm{C}$ patients that underwent treatment with IFN regimens and reached SVR, a significant reduction in HCC incidence has been reported ${ }^{(29-31)}$. However, in patients with cirrhosis, despite incidence reduction, a relevant risk of HCC remains, and thus HCC screening should be continued in these patients ${ }^{(30,32)}$. Over the past decade, with the advent of direct-acting antivirals (DAAs), we have seen a significant change in the hepatitis $\mathrm{C}$ treatment landscape, leading to high rates of SVR, above $95 \%$. Another 
remarkable change with DAAs, is the possibility to treat patients with decompensated cirrhosis, due to improved drug tolerance and low side effects, not possible in the pegylated IFN era ${ }^{(33)}$.

However, the impact of DAAs on the incidence and risk of HCC recurrence has become a subject of great debate in the literature. Several studies analyzing this issue have shown discordant results. Study quality and heterogeneity preclude a more definitive conclusion. Some early studies have suggested a higher incidence of HCC in patients with SVR treated with DAAs compared with patients treated with IFN. On the other hand, some studies have shown higher and earlier HCC recurrence rates in patients treated with DAAs, with a previous history of HCC, and more aggressive tumor behavior ${ }^{(34,35)}$.

Several studies ${ }^{(36-39)}$ and a recently published meta-analysis did not show an increase in the incidence or recurrence of HCC with DAAs compared to IFN treatment; however, the included studies were heterogeneous and with quality limitations ${ }^{(40)}$. This remains a controversial topic, and it seems essential to maintain close vigilance in post-DAA SVR patients with advanced liver disease, especially in those with a history of HCC treated with complete response ${ }^{(41)}$.

Epidemiological and case-control studies have shown the protective effect of coffee in preventing the development of HCC in patients with liver disease ${ }^{(42-45)}$. However, there are no randomized controlled intervention studies evaluating this topic, and the available studies are heterogeneous.

\section{Recommendations}

- Universal hepatitis B immunization is recommended (high level of evidence; strong recommendation).

- Effective antiviral therapy, given as early as possible, is recommended for patients with $\mathrm{HCV}$ infection and, where indicated, for patients with chronic HBV hepatitis (high level of evidence; strong recommendation).

- Patients with hepatitis $C$ with advanced liver disease or cirrhosis treated with SVR are still at risk of developing HCC, and thus should be maintained in HCC screening programs (high level of evidence; strong recommendation).

- The impact of treating HCV with DAAs on tumor recurrence in patients with $\mathrm{HCC}$ treated with curative intent is still uncertain, and further studies are needed to define this correlation. It is recommended that treatment with these medications should be initiated at least six months after complete tumor response in patients with early HCC (low level of evidence; weak recommendation).

- Alcoholic beverages are carcinogenic, and its abuse should be avoided. In patients who already have chronic liver disease, alcohol consumption may increase the risk of HCC (high level of evidence; strong recommendation).

- Management of diabetes mellitus and obesity in patients with liver disease, and lifestyle modifications in those with NAFLD may reduce the risk of HCC (high level of evidence; strong recommendation).

\section{SURVEILLANCE}

Due to increased incidence and HCC mortality, the need for surveillance programs in cirrhotic patients, in which $90 \%$ of primary liver tumors occur, has become imperative. Screening for HCC has been progressively adopted and recommended worldwide, as there is a well-defined population at risk - patients with cirrhosis and curative treatments, such as ablative therapies, liver resection (LR), and liver transplantation (LT), are available for tumors diagnosed at early stages. Nowadays, the recommended screening image method for HCC is an abdominal ultrasound, which is a cost-effective, noninvasive and a widely available diagnostic tool ${ }^{(46-48)}$.

The main goal of any surveillance program is to reduce mortality. There are three randomized controlled trials (RCT) on HCC surveillance ${ }^{(49-51)}$, and one of these trials was conducted by Zhang et al. ${ }^{(50)}$. In this study, randomization was made comparing abdominal ultrasound and alpha-fetoprotein (AFP) surveillance every six months vs absence of surveillance in cases of chronic HBV infection, despite the presence of cirrhosis. Regardless of low adherence to screening $(55 \%)$, HCC-related mortality was reduced by $37 \%$ in the surveillance $\operatorname{arm}^{(50)}$.

Most of the other studies that analyzed the role of HCC surveillance were nonrandomized cohort studies, population-based or not, and economic and public health-focused studies, such as costeffectiveness analyses. Despite the heterogeneity of methodology, stages, and etiology of liver disease, and variations in surveillance protocols, these studies have shown favorable results for the use of screening in comparison to increased lives saved ${ }^{(52-61)}$.

It has been shown that, in a setting where the incidence of HCC is higher than or equal to $1.5 \%$ /year, surveillance is cost-effective, so screening for HCC in cirrhotic patients is indicated regardless of etiology ${ }^{(62,63)}$. Non-cirrhotic HCV patients with advanced fibrosis (F3) have a significant risk of sub staging and are also considered to be at increased risk for HCC and thus should be included in surveillance programs ${ }^{(47)}$.

Patients with chronic HBV infection are at increased risk for $\mathrm{HCC}$, even in the absence of cirrhosis ${ }^{(64)}$. Therefore, non-cirrhotic hepatitis B patients with risk factors for developing HCC should be considered for screening ${ }^{(64,65)}$.

Up to $50 \%$ of HCC cases in NAFLD patients are estimated to occur outside the context of advanced fibrosis or cirrhosis ${ }^{(66-69)}$. In Brazil, a study demonstrated that $31 \%$ of patients with NAFLD and HCC did not have cirrhosis ${ }^{(21)}$. However, there is still no scientific evidence and cost-effectiveness studies to support screening in NAFLD patients without cirrhosis.

$\mathrm{HCC}$ screening can be performed by serological and imaging tests. Abdominal ultrasound is the most widely used and accepted method for screening. It has a sensitivity ranging from $60 \%-80 \%$, with specificity greater than $90 \%$, which guarantees a good diagnostic accuracy ${ }^{(46,70)}$.

In a meta-analysis of 19 studies evaluating the role of ultrasound in screening for HCC, a sensitivity of $94 \%$ was observed for the overall diagnosis of HCC. However, for the diagnosis of early HCC, the sensitivity dropped to $63 \%{ }^{(70)}$. Other imaging methods such as computed tomography (CT) and magnetic resonance imaging (MRI) have not been shown to be cost-effective for HCC screening ${ }^{(46,47,63)}$.

Regarding AFP, several studies have been performed, some showing benefit in the use of AFP and others not. In the metaanalysis published by Singal et al. ${ }^{(70)}$, the association of AFP and ultrasound increased sensitivity for detecting early HCC from $63 \%$ to $69 \%$, with no statistical difference. However, for a proper ultrasound screening, a well-trained healthcare professional in liver ultrasound is required. Thus, in centers where there are no professionals with adequate expertise to perform the screening, AFP can be used in association with ultrasound.

The recommended interval for HCC screening is six months, and it is based on tumor doubling time $\mathrm{e}^{(46,70)}$. 


\section{Recommendations}

- Surveillance for HCC is recommended for high-risk populations and compensated cirrhotic patients are the main target population for screening (high level of evidence; strong recommendation).

- Patients with non-cirrhotic hepatitis B at high risk for developing HCC and those with chronic liver disease and advanced fibrosis (F3) should also be included in the surveillance program (moderate level of evidence; strong recommendation).

- Surveillance should be performed by abdomen ultrasound with or without AFP every six months (moderate level of evidence; strong recommendation).

\section{RADIOLOGICAL DIAGNOSIS}

Accurate diagnosis of $\mathrm{HCC}$ is critical for determining curative treatment. Multiphase CT and MRI studies are the main radiological exams used ${ }^{(47,71,72)}$.

In the process of hepatocarcinogenesis, there is a progressive increase in abnormal unpaired arteries, reduction in usual arterial flow, and reduction in portal venous supply ${ }^{(73)}$. Such changes result in the classic radiological presentation of HCC according to the radiological method used, as following:

- CT and MRI with extracellular contrast medium: hyperenhancement on arterial phase and "washout" on portal venous or delayed phase.

- MRI with hepatobiliary-specific contrast medium: hyperen- hancement on arterial phase and "washout" on portal venous or delayed phase. In the hepatobiliary phase, HCC usually does not retain the hepatospecific contrast medium, but well-differentiated tumors may maintain a similar or higher concentration of contrast when compared to the liver.

- Contrast-enhanced ultrasound (CEUS): arterial hyper enhancement and mild and late-onset "washout" (after 60 seconds of contrast-medium injection).

The presence of the typical pattern on CT and MRI of arterial hyperenhancement and "washout" on portal venous or delayed phase have sensitivity between $66 \%$ and $82 \%$ and specificity above $90 \%$ for the diagnosis of $\mathrm{HCC}$ in patients with cirrhosis and nodules larger than $1 \mathrm{~cm}$ in diameter ${ }^{(74)}$. Most studies show a tendency toward higher sensitivity with the use of MRI compared to CT.

The diagnostic performance may vary according to lesion size, with better MRI performance being observed in smaller nodules (sensitivity of $48 \%$ and $62 \%$, respectively, for CT and MRI in tumors smaller than $2 \mathrm{~cm}$ vs $92 \%$ and $95 \%$ for CT and MRI, respectively, in tumors equal to or larger than $2 \mathrm{~cm})^{(75)}$. Regarding MRI with hepatobiliary-specific contrast medium, further studies are needed for a definitive conclusion ${ }^{(75-78)}$.

Even with the increase in sensitivity and specificity of diagnostic tests over the years, the diagnosis of HCC after detecting a nodule during screening ultrasound in the cirrhotic patients remains a challenge. The proposed flowchart for the diagnosis of HCC in cirrhotic patients takes into account the size and typical imaging features of HCC (FIGURE 1).

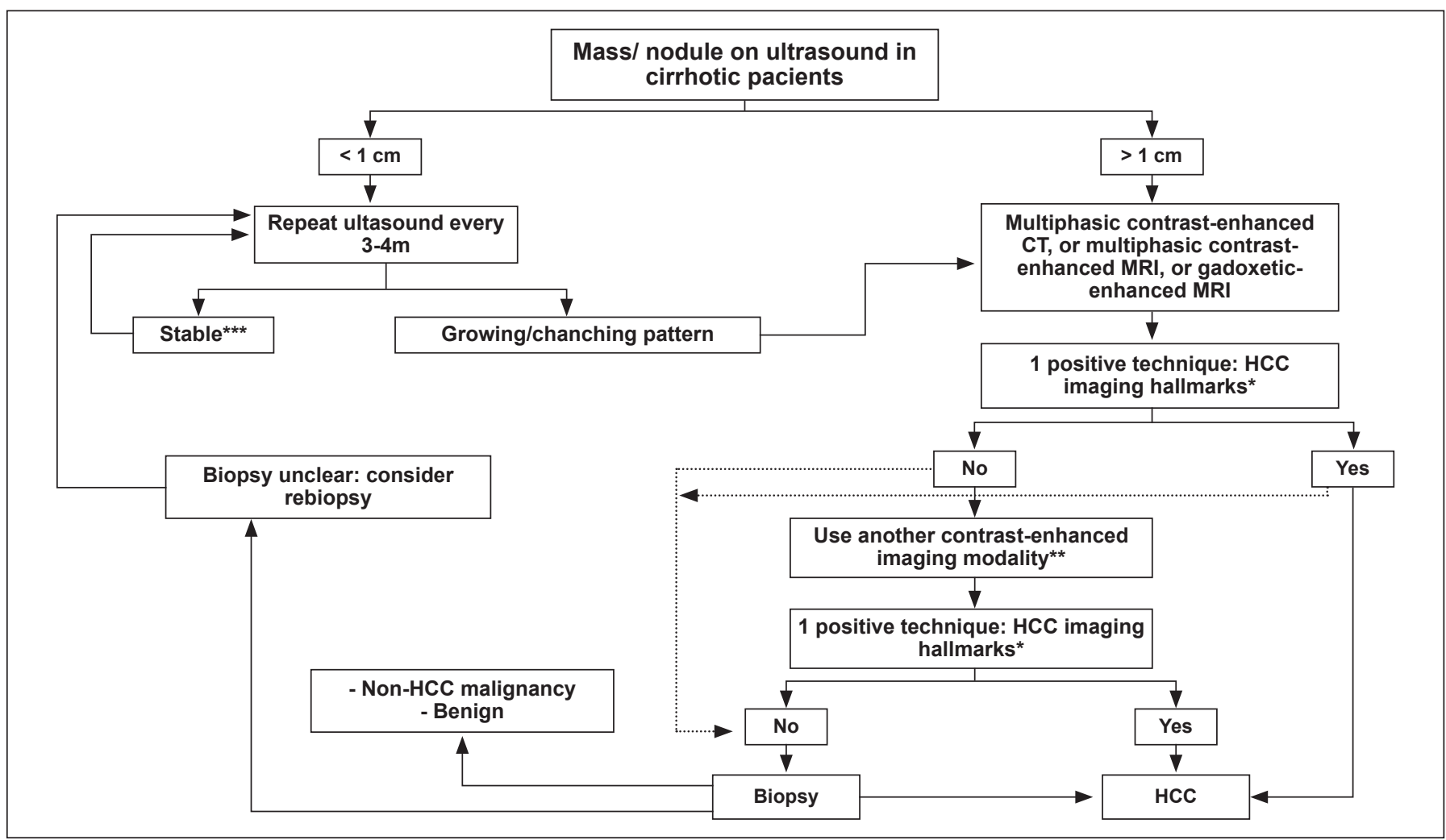

FIGURE 1. Hepatocellular carcinoma diagnostic flowchart in patients with cirrhosis. *Typical pattern for HCC: hyperenhancement on arterial phase and "washout" on portal venous or delayed phase. **Contrast enhanced abdominal CT or contrast enhanced MRI using an extracellular contrast agent or contrast enhanced MRI using hepatobiliary contrast agents or contrast-enhanced US. ***Nodules $<1 \mathrm{~cm}$ after stability for 12 months may return to the screening interval every $6 \mathrm{~m}$. This algorithm was adapted from the European Association for the Study of the Liver (EASL) guideline ${ }^{(47)}$. 
Due to the heterogeneity of HCC features over hepatocarcinogenesis, the complexity of treatment of these patients, and the possibility of other malignant lesions in cirrhotic patients, a more reproducible and objective system of classification of focal hepatic lesions has become necessary in this group of high-risk patients for HCC. In this context, the LI-RADS ${ }^{\circledR}$ (Liver Imaging Reporting And Data System) emerged with the aim of standardizing the imaging technique and terminology used to describe focal liver lesions, as well as to assist in the interpretation of results and in the standardization of reports ${ }^{(79-81)}$.

The following diagnostic categories are used in the CT/MRI LI-RADS ${ }^{\circledR(79,80)}$ : LR-NC: not categorizable due to image omission of relevant study phases or image degradation; LR-1: definitely benign; LR-2: probably benign; LR-3: intermediate probability of malignancy; LR-4: probably HCC; LR-5: definitely HCC; LR-M: probably or definitely malignant but not HCC specific; and LRTIV: definite tumor in vein.

\section{Recommendations}

- The diagnosis of HCC in cirrhotic patients can be made by noninvasive methods and/or biopsy. (high level of evidence; strong recommendation).

- Multiphase CT or MRI studies are the basis for the diagnosis of $\mathrm{HCC}$ in the high-risk population. (High level of evidence; strong recommendation).

- CEUS can be used to diagnose HCC in the high-risk population in patients with contraindications to CT and MRI. (moderate level of evidence; weak recommendation).

- Cirrhotic patients with nodules detected on ultrasound with a diameter of less than $1 \mathrm{~cm}$ and no diagnosis established by other imaging modalities should be followed with ultrasound every 3-4 months. (moderate level of evidence; strong recommendation).

- Nodules larger than $1 \mathrm{~cm}$ detected on ultrasound in cirrhotic patients require further CT or MRI investigation. (moderate level of evidence; strong recommendation).

- In patients with cirrhosis and nodule larger than $1 \mathrm{~cm}$ in diameter, if imaging findings are typical for $\mathrm{HCC}$, the lesion should be treated without the need for liver biopsy. (high level of evidence; strong recommendation).

- If radiological findings are not typical or the enhancement pattern is atypical, a second dynamic imaging study (using another imaging modality) or lesion biopsy should be performed. (moderate level of evidence; strong recommendation).

- MRI with hepatobiliary-specific contrast medium may be useful in the differential diagnosis of minor liver lesions and may aid in differentiating between HCC and benign nodules (moderate level of evidence; strong recommendation).

- LI-RADS ${ }^{\circledR}$ can be used as a tool to assist in the diagnosis of HCC by standardizing the terminology used to describe focal liver lesions and assisting in the interpretation of results. (moderate level of evidence; weak recommendation).

\section{HCC ANATOMOPATHOLOGICAL DIAGNOSIS}

The vast majority of hepatocellular carcinomas arise in patients with underlying chronic liver disease/cirrhosis. Of the few HCCs that occur in non-cirrhotic livers, fibrolamellar carcinoma (FLC) and hepatocellular carcinoma in adenomas are the most relevant ${ }^{(9)}$. In all of these clinical and epidemiological landscapes, the pathological examination has been performed on needle biopsies, autopsies, partial resection or explant surgical specimens.

Lesions detected by imaging fit the concept of macronodule, which is defined as a nodule that is distinguished from adjacent cirrhotic nodules by size, color, and texture. It is important to acknowledge that different liver diseases lead to nodules with different features. Macronodules have a minimum diameter of 0.8 to $1.0 \mathrm{~cm}$, rarely exceeding $3 \mathrm{~cm}$, and at that point most of these nodules have already met criteria for $\mathrm{HCC}^{(82)}$.

The most accepted histological criteria for the diagnosis of macronodules are summarized in TABLE ${ }^{(82)}$. Thus, for the differential diagnosis between the HCC and other macronodules, the most important criteria to be evaluated are the presence of architectural atypia, cellularity, and presence of nuclear atypia ${ }^{(82)}$. When only some of these criteria are present, usually in nodules measuring between $1.0-2.0 \mathrm{~cm}$, the morphological evaluation for the differentiation between dysplastic nodules and small and welldifferentiated $\mathrm{HCC}$ is complemented with immunohistochemistry to detect glypican-3, glutamine synthetase, HSP-70, CD34, keratin-19, and clathrin ${ }^{(83-85)}$. The criteria used to distinguish between dysplastic nodules and HCC are the same as those used for HCC histological grading, which is based on architectural alterations, cellularity, and nuclear and nucleolar atypia ${ }^{(86)}$.

TABLE 2. Histological criteria for macronodule diagnosis.

\begin{tabular}{ll}
\hline Nodule & Histological features \\
\hline $\begin{array}{l}\text { Regenerative } \\
\text { macrodule }\end{array}$ & $\begin{array}{l}\text { A nodule larger than adjacent cirrhotic } \\
\text { nodules, but histologically similar to them. } \\
\text { Nodule (LGDN) }\end{array}$ \\
$\begin{array}{l}\text { Nodule whose cells look similar to mature } \\
\text { hepatocytes with minor architectural or } \\
\text { cytological atypia. }\end{array}$ \\
$\begin{array}{l}\text { Pysplastic Nodule } \\
\text { (HGDN) }\end{array}$ & $\begin{array}{l}\text { architectural atypia ("cell crowding”), but not } \\
\text { enough for the diagnosis of HCC. }\end{array}$ \\
\hline $\begin{array}{l}\text { Small HCC (less than } \\
2 \mathrm{~cm})\end{array}$ & $\begin{array}{l}\text { Early HCC: nodular type with indistinct } \\
\text { margins, with cells presenting minor atypia } \\
\text { and foci of stromal invasion. }\end{array}$ \\
& $\begin{array}{l}\text { Progressive HCC: nodular type. Cells may } \\
\text { presente mild or moderate atypia }\end{array}$ \\
\hline
\end{tabular}

Adapted from "The International Consensus Group for Hepatocellular Neoplasia”; Hepatology. $2009^{(82)}$.

When HCCs are poorly differentiated, the main issue is distinguishing them from cholangiocarcinoma or metastatic neoplasms. Especially in these situations, immunohistochemistry may also help in distinguishing between HCC and other adenocarcinomas ${ }^{(84)}$. HCC subtypes, some of which are already well characterized in their morphological and molecular profiles, have been described, including FLC $^{(87)}$; scirrhous hepatocellular carcinoma ${ }^{(88)}$; steatohepatic $\mathrm{HCC}^{\left({ }^{(8)}\right.}$; HCC with lymphoid stroma, clear-cell variant of HCC and sarcomatous $\mathrm{HCC}^{(90)}$. On the other hand, the identification of molecular profiles by gene expression, DNA sequencing or RNA sequencing techniques or even combined approaches has brought new proposals for the classification of HCC based on genetics, highlighting, in summary, two major types:

1. High proliferative $\mathrm{HCC}$, with at least progenitor cell subtype and p53 mutated;

2. Low proliferative, with at least Beta-catenin mutated subtype and Metabolic disease-associated tumors ${ }^{(15,90-92)}$.

Precise diagnosis of $\mathrm{HCC}$ is fundamental for determining treat- 
ment and prognosis; however, the diagnostic accuracy of imaging studies is quite variable ${ }^{(93)}$. About $30 \%-40 \%$ of patients will need a biopsy to confirm diagnosis ${ }^{(94)}$. In small nodules, false-positive diagnosis on imaging exams may lead to incorrect organ allocation for transplantation ${ }^{(95,96)}$. In one study, $31 \%$ of patients who underwent liver transplantation for nodules smaller than or equal to 1.9 $\mathrm{cm}$ on imaging exams had no evidence of tumor in liver explants ${ }^{(95)}$.

As depicted at FIGURE 1, nodules larger than $1 \mathrm{~cm}$ in diameter, when dynamic imaging exams do not show typical vascular characteristics may require biopsy to yield a more precise diagnosis ${ }^{(47)}$. The risk of tumor spread in the biopsy needle path, although real ${ }^{(97)}$, seems to be overestimated and has been consistently reported as not relevant to the patient's prognosis ${ }^{(98,99)}$. Other risks, including death, are low, and thus biopsy should not be avoided when necessary ${ }^{(100)}$.

Biopsy is essential for diagnosis in cases of nodules in patients without cirrhosis and when intrahepatic cholangiocarcinoma or hepato-cholangiocarcinoma is suspected ${ }^{(101)}$. Important additional benefits from biopsy are the assessment of prognosis through the degree of histologic differentiation and the potential detection of presence of microvascular invasion (although hard to evaluate in needle biopsies), as well as the possibility of obtaining material for biomarkers which may drive therapeutic studies ${ }^{(102)}$.

\section{Recommendations}

- In non-cirrhotic patients, the diagnosis of HCC should be confirmed by biopsy (moderate level of evidence; strong recommendation).

- Patients with cirrhosis and nodules larger than $1 \mathrm{~cm}$ in diameter and without typical HCC features on a first dynamic imaging examination (MRI or CT) may undergo another imaging modality or nodule biopsy for diagnostic clarification (moderate level of evidence; strong recommendation).

- Another biopsy is recommended in cases of inconclusive histology or discordant findings (low level of evidence; strong recommendation).

\section{STAGING AND CLASSIFICATION FOR TREATMENT ALLOCATION: A NEW LOOK AT BCLC}

HCC staging and classification are essential for prognostic determination, treatment definition, as well as for the standardization of clinical trials ${ }^{(103)}$.

Most HCC staging systems take into account not only tumor burden but also the underlying liver function (as the vast majority of tumors occur in cirrhotic patients) and the presence of tumor-related symptoms ${ }^{(104)}$. An ideal system should make the connection between disease stage and recommended therapeutic proposals. In this regard, the Barcelona Clinic Liver Cancer (BCLC) classification accomplishes these goals ${ }^{(105)}$. This system has been extensively used worldwide ${ }^{(106)}$ and in Brazil ${ }^{(1,107)}$. Importantly, several other classifications are mentioned in American, European, and Asian literature such as TNM, Cancer of the Liver Italian Program (CLIP), Hong Kong Liver Cancer (HKCL), and Japanese Integrated Staging (JIS) score ${ }^{(108-111)}$.

Since 1999 when it was first published, the BCLC has continuously been updated in line with emerging scientific evidence that is robust enough to change clinical practice. The latest version of BCLC was published in 2018 ${ }^{(105)}$, and it offers five stages for HCC classification, called Stage 0 (Very early stage), Stage A (Early stage), Stage B (Intermediate stage), Stage C (Advanced stage), and Stage D (Terminal stage) (FIGURE 2). In all but BCLC D, the

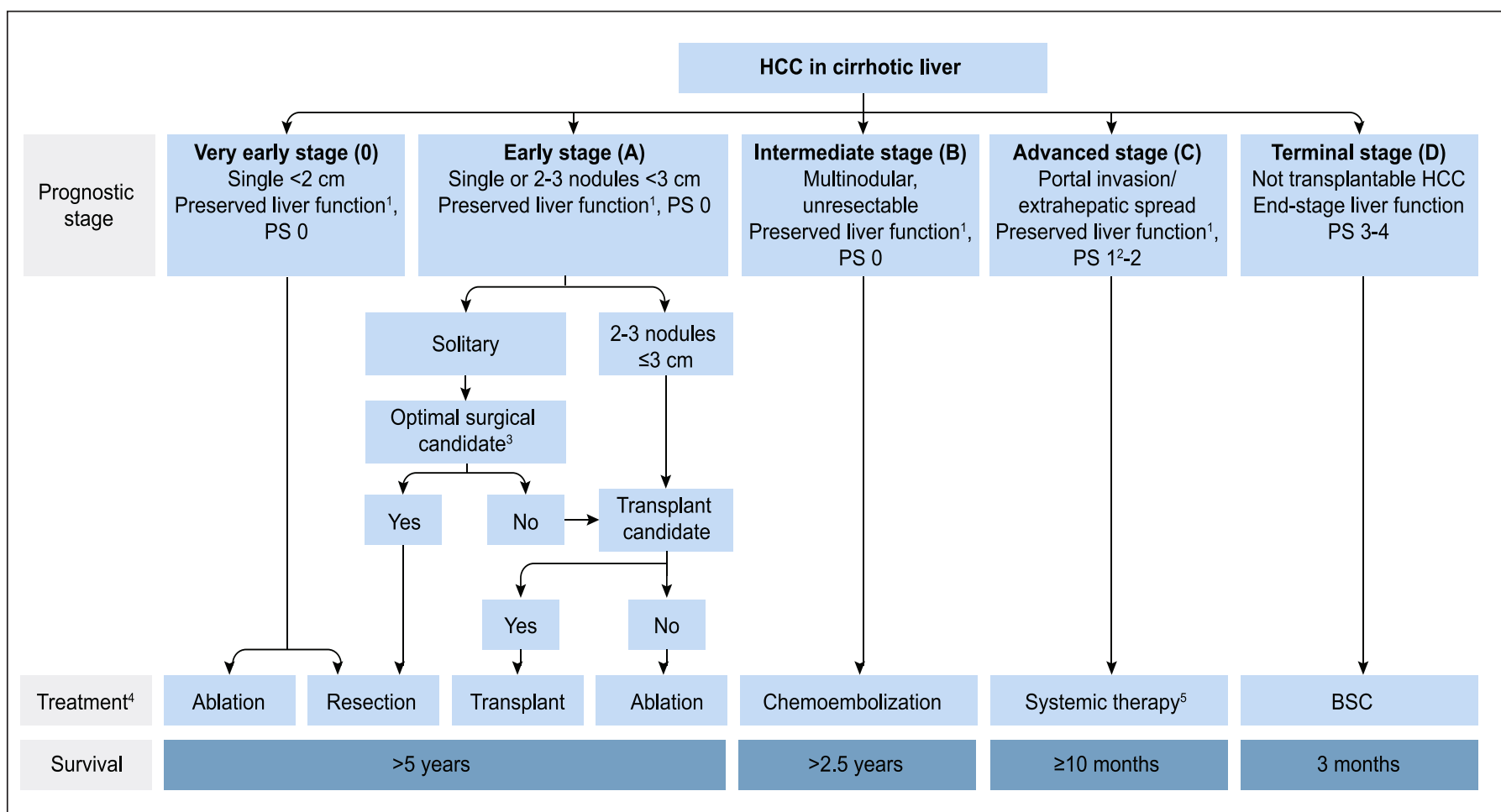

FIGURE 2. Hepatocellular carcinoma algorithm for staging and treatment, according to BCLC recommendations (modified from Forner A, Reig M and Bruix J, 2018 $\left.{ }^{(105)}\right)$. 
proposed treatments offer an increase in survival. The previously used terms such as "curative" or "palliative" treatments have been replaced in this new version. Survival expectations according to the stages are: more than five years for BCLC 0 and A, more than 2.5 years for BCLC B and about one year for BCLC C. At the terminal stage, about three months of overall survival is expected.

A patient in BCLC stage 0 corresponds to a patient who has preserved liver function, with no cancer-related symptoms classified as Eastern Cooperative Oncology Group Performance Status (ECOG-PS - TABLE 3) 0 and with a single tumor, smaller than 2 $\mathrm{cm}$. For such patients, it is possible to offer a curative treatment, with 5-year survival ranging from $60 \%$ to $80 \%$, which may exceed $95 \%$, with a low risk of tumor recurrence. The main treatment options are surgery and percutaneous ablative therapies ${ }^{(104,105)}$.

BCLC A stage patients are those with a single tumor or up to three nodules $<3 \mathrm{~cm}$, with preserved liver function and ECOG-PS 0 . Patients in this stage should be evaluated for liver resection, liver transplantation, or radiofrequency ablation (RFA), according to liver function using the Child-Pugh (CP) classification, and the presence of portal hypertension ${ }^{(105)}$. There are no RCT comparing available therapeutic modalities (LT, LR, and RFA) for patients with early HCC. Patients with single nodules, preserved liver function (CP A), and without portal hypertension should be evaluated for surgical treatment ${ }^{(112)}$. The 5 -year survival rate for patients receiving $\mathrm{LR}$ is around $70 \%$, in patients with preserved liver function. In the presence of portal hypertension, this survival rate may drop to $50 \%{ }^{(113)}$.

TABLE 3. Eastern Cooperative Oncology Group Performance Status Cancer-Related Symptom of Cancer-Related Symptoms (ECOG-PS).

0 Fully active, able to carry on all pre-disease performance without restriction

1 Restricted in physically strenuous activity but ambulatory and able to carry out work of a light or sedentary nature, e.g., light house work, office work

2 Ambulatory and capable of all selfcare but unable to carry out any work activities; up and about more than $50 \%$ of waking hours

3 Capable of only limited selfcare; confined to bed or chair more than $50 \%$ of waking hours

4 Completely disabled; cannot carry on any selfcare; totally confined to bed or chair

5 Dead

Liver transplantation is the treatment of choice for patients with early HCC, impaired liver function and/or portal hypertension $^{(104,105)}$. For patients who are within the Milan Criteria (MC) - a single tumor $\leq 5 \mathrm{~cm}$ or up to 3 nodules $\leq 3 \mathrm{~cm}$ without macroscopic vascular invasion or distant compromise on pretransplant imaging - the 5-year survival is around $70 \%$, with a recurrence rate of less than $15 \%{ }^{(105,112)}$. In patients with early HCC in whose LR or LT cannot be performed, RFA is the treatment of choice ${ }^{(104,105)}$. Post-ablation survival in CP A patients reaches $50 \%$ to $75 \%$ in 5 years ${ }^{(114)}$.

Patients in the BCLC stage B (intermediate-stage) have either multinodular HCC and/or unresectable tumor, with no vascular invasion or extrahepatic metastasis, preserved liver function and ECOG-PS $0^{(105)}$. The treatment of choice for this stage is transarterial chemoembolization (TACE), which has shown increased survival compared to conservative treatment, and it may reach an average overall survival greater than 30 months in selected patients $^{(105,112,115)}$

The advanced stage of HCC (BCLC stage C) includes patients with mild cancer-related symptoms (ECOG-PS 1-2) and/or vascular invasion or extrahepatic metastases, with preserved liver function $^{(105)}$. Patients' life expectancy at this stage varies between 4-10 months. In this stage, the treatment of choice is systemic treatment. The multikinase inhibitor (TKI) sorafenib was the first treatment that showed increased survival rates at this stage ${ }^{(116,117)}$, and it is the treatment of choice as the first line for patients with advanced $\mathrm{HCC}^{(105)}$. In phase III REFLECT trial, Levantinib was non-inferior to sorafenib as a first-line treatment ${ }^{(118)}$. Second-line treatment options for patients with advanced HCC include Regorafenib ${ }^{(119)}$, for patients with good tolerance to Sorafenibe, and more recently Cabozatinib ${ }^{(120)}$.

BCLC D comprises patients with end-stage HCC. This group includes non-liver transplant patients with severe liver dysfunction and/or severely deteriorated physical condition, defined as ECOG-PS greater than $2^{(105)}$. At this stage, patients have a very poor prognosis and are candidates for best supportive care, with overall survival of three months ${ }^{(105)}$.

A significant percentage of patients, however, do not the meet criteria for treatment allocation determined by their stage. In these cases, the concept of stage migration is applied, and the patient should be offered the next available treatment within his stage or the treatment of choice for the subsequent stage ${ }^{(105)}$. Thus, patients with early $\mathrm{HCC}$ who have contraindications to surgery, ablative therapies or transplantation should migrate to the treatment of choice of the intermediate stage and undergo TACE. Similarly, for intermediate-stage (BCLC B) patients with contraindications to TACE, systemic treatment should be offered ${ }^{(105)}$.

It should be emphasized that the therapeutic decision in patients with HCC is a complex task, as multiple factors should be taken into account, such as number, size and tumor location, liver function, presence or absence of portal hypertension, patient's general condition, and the presence of comorbidities ${ }^{(105)}$. Ideally, treatment for HCC should be discussed in a multidisciplinary setting, involving several specialties, such as hepatologists, surgeons, interventional radiologists, oncologists, among others, allowing a complete and individualized approach.

\section{Recommendations}

- The use of the BCLC system is recommended for prognostic prediction and therapeutic guidance (high level of evidence; strong recommendation).

- For patients who do not meet the criteria for treatment allocation determined by their stage the concept of treatment stage migration applies and the available treatment choice for the next tumor stage should be offered (high level of evidence; strong recommendation).

- The treatment choice for HCC should, whenever possible, be discussed by a multidisciplinary team, allowing a complete and individualized evaluation of the patient (low level of evidence; strong recommendation).

\section{HCC TREATMENT}

In this guideline, we chose to divide treatment indications according to the tumor stage based on the BCLC classification system. 


\section{VERY EARLY AND EARLY HCC - BCLC O AND A}

Patients who are classified as very early (BCLC 0 ) or early (BCLC A) HCC are amenable to treatment with LR, ablation or LT according to variables such as number and size of nodules, presence of portal hypertension, elevation of bilirubin or eligibility criteria for $\mathrm{LT}$ according to MC

The main therapeutic modalities for patients with BCLC 0 and A HCC and their indications will be discussed below.

\section{Percutaneous ablative therapies}

Different ablative techniques have been described and used in the treatment of HCC over the last three decades. The most available percutaneous ablative therapies used in our country are RFA and percutaneous ethanol injection (PEI). Other modalities of percutaneous ablative therapies are cryoablation, microwave ablation, or high-intensity focused ultrasound (thermal ablation). However, as these methods are not widely available in our country, they will not be addressed ${ }^{(121,122,123)}$.

Several meta-analyses performed to compare PEI vs RFA have shown that RFA is superior to PEI in terms of overall survival, disease-free survival, and recurrence rates ${ }^{(124-127)}$. However, in tumors $\leq 2 \mathrm{~cm}$, both RFA and PEI achieve high rates of tumor necrosis and complete response ${ }^{(124,128)}$. For tumors between 2 to $3 \mathrm{~cm}$ RFA is the treatment of choice ${ }^{(124,129-132)}$. Combined therapy using the combination of percutaneous ablative modalities with other techniques, such as TACE, has shown promising results, especially for tumors between $3-5 \mathrm{~cm}$. However, the results available so far are from retrospective and RCTs with significant selection bias ${ }^{(129)}$.

When RFA was compared to LR, in a Cochrane review that included 574 patients with early HCC candidates for LR, no differences in mortality rates were found. Although the $\mathrm{HCC}$ recurrence rate was lower in the LR group, adverse events were less frequent in the RFA group ${ }^{(133)}$. In addition, RFA proved to be more cost-effective than LR in very early HCCs in CP A patients and the presence of two or three nodules $<3 \mathrm{~cm}$. For single 3 to $5 \mathrm{~cm} \mathrm{HCC}$, LR provided better life expectancy and was more cost-effective than $\mathrm{RFA}^{(134)}$.

Tumor location is a critical factor in decision-making. In central localized tumors, which imply substantial parenchymal loss at surgery, the use of RFA is favored, although proximity to vascular and biliary structures may be a problem ${ }^{(135)}$. Relative contraindications for RFA include tumor adjacent to large vessels, to extrahepatic organs, or liver capsule. Absolute contraindications include tumors adjacent to large bile ducts, decompensated cirrhosis ( $\mathrm{CP} \geq \mathrm{B} 9)$, or recent history of cirrhosis complications such as severe ascites, encephalopathy, and upper gastrointestinal bleeding ${ }^{(129,135)}$.

\section{Surgical treatment}

Liver resection is one of the main therapeutic options in BCLC 0 and $\mathrm{A}$ tumors, but its indication in patients with cirrhosis depends on the expected functional capacity of the remaining liver, in addition to the number and location of nodules, patient's ECOG-PS and comorbidities ${ }^{(47)}$.

LR and LT are considered potentially curative treatments for HCC. LR is the treatment of choice for HCC in the non-cirrhotic liver, and in cirrhotic patients with very early (BCLC 0 ) or early (BCLC A) stage and preserved liver function in the absence of portal hypertension. Liver transplantation, on the other hand, is considered the ideal curative treatment for patients with decompensated cirrhosis (CP B or C) and early or very early HCC, within the $\mathrm{MC}^{(47,136)}$. However, organ supply is still insufficient to enable LT for all listed patients. This affects the overall outcomes of LT, either by death in the transplant waiting list or dropout due to disease progression ${ }^{(137)}$.

As a general rule, 5-year survival rates for patients with $\mathrm{HCC}$ after LR are between $50 \%$ and $70 \%$ and, after LT, between $70 \%$ and $80 \%{ }^{(138-141)}$. The tumor recurrence rate after LR is around $50 \%$ and post-LT around $10 \%{ }^{(140-143)}$. However, considering the long time spent on the waiting list (over 6-9 months), when an intention-totreat analysis is performed, similar survival outcomes are found when comparing LR with $\mathrm{LT}^{(137,144)}$.

In general, LR is indicated for patients with single nodules and compensated liver function (CP A). The presence of portal hypertension, characterized by hepatic venous pressure gradient $\geq 10 \mathrm{mmHg}$ or presence of esophageal varices, splenomegaly, and thrombocytopenia, is a strong predictor of worse survival after $\mathrm{LR}^{(113,145)}$.

However, the evolution of surgical techniques and perioperative care has allowed the expansion of liver surgery indications ${ }^{(47)}$. Thus, limited LR in patients with preserved liver function, small-sized esophageal varices, and platelet counts above 100,000 is feasible in selected patients with "mild" portal hypertension ${ }^{(138,141,146)}$. Nevertheless, it is noteworthy that even CP A patients can decompensate after major resections ${ }^{(140)}$.

Regarding major liver resections (more than three liver segments), the remaining liver volume is the most important predictor of postoperative liver failure; therefore, a total remaining liver volume of at least $40 \%$, is advisable. When the expected remaining liver volume is less than $40 \%$, a preoperative selective contralateral portal vein embolization may be useful to increase the remaining volume ${ }^{(147)}$.

MELD (Model For End-Stage Liver Disease) score ${ }^{(148)}$ may also be a prognostic indicator of liver failure after LR. Studies suggest that patients undergoing surgery with a MELD score of less than 10 had low rates of postoperative liver failure, regardless of the extent of $\mathrm{LR}^{(149,150)}$.

Laparoscopic LR is a less invasive approach that has been increasingly used for HCC treatment. It is comparable to open surgery in terms of oncologic outcomes, and survival and it offers advantages such as reduced blood loss, lower morbidity (less postoperative ascites), and shorter hospital stay ${ }^{(151-153)}$. The availability of laparoscopic surgery is undoubtedly an additional argument in favor of LR as a treatment modality for HCC.

\section{Liver transplantation}

Liver transplantation is the treatment of choice for patients with early HCC and impaired liver function and/or portal hypertension. LT has the advantage that, with liver replacement, in addition to treating the $\mathrm{HCC}$, it also enables the treatment of the underlying disease, the cirrhosis ${ }^{(104)}$. In the last two decades, there has been significant growth in the number of LT in Brazil. For this reason, the country has become the largest public transplant system, occupying the second position worldwide in absolute numbers of LTs performed per year. Notwithstanding, Brazil is on the 29th position in the number of donors around the globe ${ }^{(154)}$.

After the adoption of the Milan Criteria, there was a significant improvement in post-transplant overall survival of patients with $\mathrm{HCC}$, reaching $75 \%$ in five years, with tumor recurrence rates ranging from $8 \%-20 \%{ }^{(136,155-157)}$. HCC represents one of the main indications for LT in Brazil nowadays and worldwide, accounting for $15 \%-50 \%$ of transplants performed in most centers ${ }^{(158-161)}$.

From their introduction by Mazzafero et al. in 1996 to the pre- 
sent day, the MC have been established as a reference for patient's inclusion on the transplant waiting list and is the selection criteria adopted in most centers ${ }^{(136,158,162,163)}$. Several subsequent studies and a meta-analysis confirmed the strong association of $\mathrm{MC}$ with better post-transplant survival and lower risk of selecting patients with more aggressive tumor biological behavior ${ }^{(164)}$. According to European and American registries, 5-year overall survival in transplanted patients within MC $(65 \%-85 \%)$ is similar to those transplanted without HCC $(65 \%-87 \%)^{(165)}$.

Yet, in the last decades, MC have been criticized for being based exclusively on imaging exams and for being considered too restrictive ${ }^{(158,162)}$. Although some studies using expanded criteria have shown survival rates similar to those observed within $\mathrm{MC}$, the use of these expanded criteria is not yet consensual and most countries in the world still use MC or similar systems for HCC patient's selection for $\mathrm{LT}^{(166-172)}$. Currently, there is a great discussion over the adequate selection criteria for LT. For a better selection, besides tumor size and number of nodules, other features that reflect tumor biological behavior, such as the degree of tumor differentiation, AFP and response to locoregional treatment should be included ${ }^{(166,173,174)}$.

Organ scarcity in various regions, with consequent long waiting time in the LT list, has led to an increased risk of death and dropout. Bridging treatment for $\mathrm{HCC}$ is recommended in regions where the waiting time in the list is longer than six months to prevent tumor progression $^{(47,166,175)}$. The most commonly used therapeutic modalities are TACE and RFA. There are no randomized controlled trials demonstrating the superiority of one therapy over another as a bridge to liver transplantation ${ }^{(166,175)}$.

Evaluation of response to locoregional treatment, while on the waitlist, should be performed at three-month intervals by radiological evaluation using the mRECIST (Modified Response Evaluation Criteria in Solid Tumors) criteria ${ }^{(176)}$ and biological markers dosage such as $\mathrm{AFP}^{(177)}$.

In 2006, Ordinance n. 1,160 modified the liver distribution criteria for LT in Brazil by implementing the MELD system. HCC was classified as a "special situation", earning extra points from time to time, reaching a maximum score of 29 points in six months on the waitlist ${ }^{(178)}$. The selection criteria adopted for HCC is an expanded version of the classic MC so-called "Brazilian Milan Criteria" (BMC) and takes into consideration only nodules with a radiological diagnosis of $\mathrm{HCC}$ larger than $2 \mathrm{~cm}$. Patients with $\mathrm{HCC}$ are eligible for "HCC exception score" if they present one nodule from 2 to $5 \mathrm{~cm}$ or up to three nodules between 2 and $3 \mathrm{~cm}$, plus any number of nodules less than $2 \mathrm{~cm}$. However, a recent national multicenter study showed worse survival and higher tumor recurrence rates in those patients within the BMC for LT when compared to those submitted to LT within MC (when considering imaging at the time of listing, as well as the explant data). In this study, AFP and the presence of vascular invasion in the explant were important predictors of tumor recurrence and survival ${ }^{(179)}$.

\section{Recommendations}

- RFA is the treatment of choice for patients with very early (BCLC 0 ) or early (BCLC A) HCC who are not candidates for liver resection or liver transplantation, whenever technically feasible, preferably in patients with tumors $<3 \mathrm{~cm}$ (high level of evidence; strong recommendation).

- In patients with very early HCC (BCLC 0$)$ and single tumors less than $2 \mathrm{~cm}$, in favorable locations, RFA can be adopted as the first choice, even in patients who are candidates for surgery (moderate level of evidence; strong recommendation). In patients with single tumors of 2 to $3 \mathrm{~cm}$ who are candidates for LR, RFA may be considered as an alternative to surgery, depending on the tumor's location and patient's clinical status.

- PEI might be recommended in cases of very early (BCLC 0) and early (BCLC A) HCC, when RFA is not technically possible or unavailable, especially in tumors smaller than $2 \mathrm{~cm}$. (high level of evidence; strong recommendation). However, in lesions $>2 \mathrm{~cm}$, PEI should be discouraged by its association with high rates of incomplete response and local recurrence.

- Liver resection is the main therapeutic option for HCC in non-cirrhotic livers (low level of evidence; strong recommendation).

- In the cirrhotic liver, HCC resection should be considered in patients with single nodules and preserved liver function (CPS A, normal bilirubin and without $\mathrm{PH}$ ), provided that liver remnant volume is adequate (high level of evidence; strong recommendation). Selected cases with mild portal hypertension, preserved liver function, and low MELD score may benefit from LR.

- Laparoscopic LR for HCC, in specialized centers, is recommended whenever possible, especially for superficial HCC or localized anterolaterally (moderate level of evidence; weak recommendation).

- After resection, close follow-up is mandatory due to the high risk of liver recurrence (high level of evidence; strong recommendation).

- Liver transplantation is the first-line treatment in patients with early HCC (BCLC A), with impaired liver function and/ or portal hypertension and in those who are not candidates for surgical treatment (high level of evidence; strong recommendation).

- The Milan Criteria are the reference for selecting HCC patients for liver transplantation and the basis for comparison with other suggested criteria (high level of evidence; strong recommendation).

- Locoregional treatment on the waitlist is recommended whenever possible, especially in locations where the waiting time on the list is longer than six months, as it reduces the risk of dropout and may lead to reduced risk of tumor recurrence after transplantation (low level of evidence; strong recommendation).

- The expanded Milan criteria ("Brazilian Milan Criteria") currently used in Brazil for HCC patient's selection for liver transplantation should be reviewed (low level of evidence, strong recommendation).

\section{INTERMEDIATE HCC - BCLC B}

This group consists of patients with multifocal tumors who do not have vascular invasion or extrahepatic metastasis, with preserved liver function and asymptomatic (ECOG-PS 0) ${ }^{(105)}$. As already stated, the treatment of choice for patients with intermediate HCC is TACE, which has shown increased overall survival rates when compared to best supportive care ${ }^{(112,115)}$. TACE is the most used technique for the treatment of $\mathrm{HCC}$ in Brazil ${ }^{(10)}$. It is noteworthy that the BCLC B is the most heterogeneous stage; thus, alternative treatment proposals such as surgery are possible.

Imaging-guided transarterial therapies lead to tumor necrosis, 
based on the fact that HCC has a predominant arterial vascularization compared to the rest of the liver parenchyma. This difference in vascularization allows the treatment of HCC through selective intravascular administration of drugs, embolic particles or radioactive devices $^{(115)}$.

Transarterial therapies available for HCC treatment include microparticles embolization without a chemotherapeutic agent, called transarterial embolization (TAE), or with the combination of a chemotherapeutic agent (usually doxorubicin or cisplatin), known as transarterial chemoembolization (TACE) ${ }^{(115)}$. In conventional TACE (TACEc), embolization is performed with microparticles emulsification with chemotherapeutic agents ${ }^{(115,180)}$.

More recently, drug-eluting beads embolization, DEB-TACE, has been introduced as an alternative to conventional TACE with the aim of improving outcomes and reducing side effects. DEB-TACE is based on the use of ion-binding microspheres capable of actively sequestering and slowly releasing cytotoxic drug within the target lesion $^{(181)}$. Another technique that employs a different approach is transarterial radioembolization (TARE). This technique consists of a selective intra-arterial administration of microspheres loaded with a radioactive compound (usually Yttrium ${ }^{(90)}$ ). It exerts its therapeutic effect through the radiation carried by these microspheres ${ }^{(182)}$.

Although initial studies have shown controversial results on the survival benefits of TACEc, a 14-study meta-analysis showed that TACEc increases the survival of patients with unresectable $\mathrm{HCC}^{(183)}$. Although TACEc is not considered a curative treatment, it is the modality of choice for patients with compensated cirrhosis and intermediate HCC (BCLC B), with ECOG-PS $0^{(105)}$.

Drug-eluting bead transarterial chemoembolization (DEB-TACE) has been launched as an alternative to TACEc, and although there is a strong rationale for the use of DEB-TACE, evidence of the superiority of this strategy over TACEc is scarce. A metaanalysis of 12 studies, including 1,449 patients, found no superiority for DEB-TACE over TACEc ${ }^{(184)}$. Most comparative studies have shown no advantage of using DEB-TACE on overall survival and clinical outcomes ${ }^{(180,185-187)}$. There are still conflicting results about DEB-TACE's safety profile compared to TACEc. Although the aforementioned meta-analysis found no differences in survival or frequency of adverse events, some studies have reported a lower incidence with DEB-TACE of liver toxicity, doxorubicin-related side effects, post-procedure abdominal pain, and general adverse events in patients with HCC greater than $5 \mathrm{~cm}$ and bilobar disease ${ }^{(185,187)}$.

Contraindications to performing TACE are described in TABLE 4.
TACE may be associated with other therapies, and some studies evaluating the combined treatment of TACE + RFA have shown promising results. In 2016, Chen et al. compared the association between RFA and TACE vs RFA. The combination demonstrated a greater benefit for patients with tumor diameters of $3 \mathrm{~cm}$ or greater ${ }^{(188)}$. However, further studies are needed to define the role of combined therapy.

Studies to date have also shown no survival benefit in combining TACE with systemic therapies such as sorafenib. In 2016, Lencione et al. performed a randomized controlled trial comparing sorafenib in combination with DEB-TACE vs isolated DEB-TACE for the treatment of intermediate HCC patients (SPACE Trial), with no benefit in time to tumor progression (TTP) or overall survival ${ }^{(189)}$. Two other studies showed similar results ${ }^{(190,191)}$.

TARE consists of an arterial infusion of radioactive substances, usually iodine-131-labeled lipiodol or yttrium-90 microspheres. It is a complex treatment that requires a multidisciplinary team. In this type of treatment, the radiotherapy effect is predominant over the embolizing effect, and it can be performed in patients with portal vein thrombosis ${ }^{(192-197)}$.

The average survival in patients treated with TARE with intermediate HCC ranges from 16.9 months to 17.2 months, and in advanced-stage patients with portal vein tumor invasion (BCLC C) ranges from 10 to 12 months $^{(198-200)}$. Liver-related toxicity and treatment-related deaths are observed, respectively, in 20\% and 3\% of patients ${ }^{(199)}$. There are no large-scale prospective randomized controlled trials comparing TARE and TACE. In a meta-analysis of eight studies, including 1,499 patients with nonresectable HCC, TARE showed a similar tumor response rate with a better safety profile and overall survival compared with TACE(201).

Since TARE is often recommended for patients with locally advanced HCC, this procedure was compared to sorafenib in two trials $^{(202,203)}$. In these studies, no differences in overall survival were observed between the two treatment strategies, although tumor response rates were significantly higher with TARE. In both trials, TARE was associated with fewer grade $\geq 3$ adverse events compared with sorafenib ${ }^{(202,203)}$. These studies indicate that TARE may be considered a therapeutic option for patients with locally advanced HCC (BCLC C), although additional data are needed to identify the subgroup of patients who would benefit the most from this treatment modality.

Other options that may be considered for BCLC B patients are systemic therapy, LR, and LT after downstaging into the MC or employing expanded criteria. Although TACE is the most widely

TABLE 4. Contraindications for performing TACE.

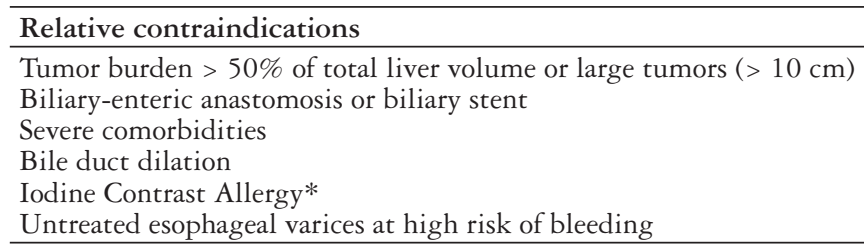

Absolute contraindications

Decompensated cirrhosis: jaundice, encephalopathy, ascites and/or hepatorenal syndrome

Child-Pugh $\geq$ B8

Macrovascular tumor invasion of the portal vein trunk or main portal branches

Reduction of portal vein blood flow (portal vein thrombosis or hepatofugal flow)

Technical contraindications to hepatic intraarterial treatment (e.g., intractable arteriovenous fistula)

Renal impairment (creatinine $\geq 2 \mathrm{mg} / \mathrm{dL}$ or creatinine clearance $\leq 30 \mathrm{~mL} / \mathrm{min}$ )

*Desensitization may be used in these cases. 
used therapeutic modality, it may not be the most appropriate choice for some BCLC B HCC patients, particularly those with more impaired liver function $(\mathrm{CP} B)^{(105)}$. A sub-classification for $\mathrm{BCLC} \mathrm{B}^{(204)}$ has been proposed. It incorporates the up-to-7 criteria into the traditional number and size of neoplastic nodules and the $\mathrm{CP}$ classification. It divides BCLC B patients into four subtypes, known as B1, B2, B3, and B4 and suggests, for each stage, other therapeutic options rather than just TACE. Equally controversial, the HKLC Classification ${ }^{(110)}$ appears to be useful in BCLC $\mathrm{B}$ patients, and it also incorporates other therapeutic options in selected cases.

Among the available treatment options, systemic therapy may be of interest in selected cases of BCLC B patients ${ }^{(205)}$. A recent review $^{(206)}$ suggests the use of sorafenib in BCLC B patients who have not responded to two cycles of TACE, or who have progressed after TACE (therapeutic migration). A recent Cochrane review of intermediate HCC, however, stresses that there is no evidence derived from RCTs supporting the use of sorafenib either alone or in combination with TACE in the treatment of intermediate $\mathrm{HCC}^{(207)}$.

On the other hand, LR may be considered for selected cases of BCLC B patients ${ }^{(208-212)}$. However, the increased risk of postoperative liver failure limits the use of LR for this group of patients. It has been the leading cause of mortality in BCLC B patients who underwent surgery, so LR has been proposed in selected cases with the association of liver transection and port vein ligation or port vein embolization of the affected segment for two-stage hepatectomy ${ }^{(150,213-216)}$.

The use of expanded criteria for LT using the University of California San Francisco (UCSF) or up-to- $7^{(168,169,217-224)}$ criteria has been associated with increased risk of tumor recurrence, not being adopted in Brazil by the National Transplant System, particularly in those patients on the LT waitlist whose disease has progressed despite locoregional treatment ${ }^{(223,224)}$.

Conversely, downstaging into MCs using locoregional therapies has been feasible in $48 \%$ of patients with BCLC-B HCC with post-transplant tumor recurrence rates of $16 \%$ to $20 \%$ over five years ${ }^{(225,226)}$. The waitlist dropout rate for disease progression, however, is high, at about $53 \%{ }^{(226)}$. There is no consensus on which exact criteria to use to determine the success of downstaging therapy, since protocols vary in the literature ${ }^{(227)}$. Regarding the type of locoregional treatment, RFA and TACE modalities have similar success rates, and adverse effects are generally low in incidence and small in proportion ${ }^{(226,227)}$. In patients undergoing downstaging using locoregional therapies, other prognostic factors should be taking into account, such as AFP levels below 500-1,000 ng/mL, and a 3-6 month observation interval after downstaging to assess the biological behavior of the tumor before listing these patients for LT.

\section{Recommendations}

- TACEc is the treatment of choice for patients with intermediate HCC (BCLC B) (high level of evidence; strong recommendation).

- There are insufficient data to recommend DEB-TACE over TACEc and the choice of technique should be based on availability, local experience, patient characteristics, and physician preferences (high level of evidence; strong recommendation).

- TACE should not be used in patients with decompensated cirrhosis, advanced renal dysfunction, macrovascular tumor invasion and extrahepatic spread (high level of evidence; strong recommendation).
- TARE is a promising therapeutic option for HCC, with a good safety profile. However, there are insufficient data favoring TARE over TACE for patients with intermediate HCC or TARE over sorafenib for patients with advanced HCC (BCLC C). (Moderate level of evidence; weak recommendation). The subgroup of patients who would benefit from TARE needs to be better defined.

- Liver transplantation may be considered for patients with BCLC B HCC after downstaging into the MC in the presence of favorable prognostic factors, including AFP levels below 500-1,000 ng/mL. (moderate level of evidence; weak recommendation). An observation period of 3-6 months after locoregional treatment is recommended to assess tumor biological behavior.

- Systemic treatment with sorafenib may be used in patients who did not respond or progressed after two cycles of TACE, or where it cannot be performed (low level of evidence; strong recommendation).

\section{ADVANCED BCLC-C HCC}

BCLC C stage comprises patients with vascular invasion or extrahepatic metastases and/or mild cancer-related symptoms (ECOG-PS 1-2), but still with relatively preserved liver function. Patients' life expectancy at this stage without treatment is 4-10 months ${ }^{(105)}$. The treatment of choice for this tumor stage is systemic therapy. Currently, most patients diagnosed with advanced HCC are treated with targeted molecular therapies or immunotherapy.

\section{Conventional systemic chemotherapy}

Treatment strategies based on conventional systemic chemotherapy have failed to demonstrate survival benefits, which have been at most around 12 months. However, in Brazil, conventional chemotherapy is still used particularly in the public health system.

Several conventional chemotherapy regimens in multiple combinations, most including oxaliplatin and/or doxorubicin, have been studied in small clinical trials in compensated patients with good ECOG-PS. Doxorubicin was one of the most studied drugs. Overall response rates ranged from $10 \%$ to $20 \%{ }^{(228-231)}$.

The mFOLFOX4 regimen was compared to doxorubicin in a randomized phase III Asian study involving 371 patients with advanced or metastatic $\mathrm{HCC}^{(232)}$. Although the response rate and median progression-free survival were higher in the mFOLFOX4 group ( $8 \%$ vs $3 \%$ and 2.93 vs 1.77 months), there was no significant difference in mean survival (6.4 vs 4.97 months, $P=0.07$ ).

Oxaliplatin was also combined with gemcitabine in a phase II study, including 32 untreated HCC patients. The response rate was $18 \%$. The median of progression-free survival and overall survival were, respectively, 6.3 months and 11.5 months $^{(233)}$. Similar results were observed in a retrospective, multicenter study that included 204 patients. Response and disease control rates were, respectively, $22 \%$ and $66 \%$, with an average overall survival of 11 months ${ }^{(234)}$.

Another platinum agent, cisplatin, has been tested in small studies combined with different drugs. In combination with capecitabine, the response rate was $6.3 \%{ }^{(235)}$, with doxorubicin $18.9 \%(236)$. and $14.5 \%$ when combined with epirubicin and capecitabine ${ }^{(237)}$.

For patients with poor ECOG or impaired liver function, including elevated bilirubin, chemotherapy options are very limited ${ }^{(238-240)}$.

The combination of target therapies and chemotherapy has been studied, but current evidence does not support its use ${ }^{(241,242)}$. 
In a study conducted in Brazil, which analyzed the role of chemotherapy as a second line of treatment in patients with advanced HCC, following sorafenib treatment failure, the authors have found high rates of chemotherapy-related adverse events, with no significant survival benefit ${ }^{(243)}$.

\section{First-line systemic therapy}

Sorafenib is an oral multikinase inhibitor that acts primarily by blocking angiogenesis and cell proliferation, and it was the first drug that showed an increase in survival rates in patients with advanced $\mathrm{HCC}^{(244)}$. This benefit was demonstrated in a prospective, randomized, placebo-controlled phase III study (SHARP study). The median survival was of 10.7 months, whereas the placebo group was 7.9 months $(P<0.001)$. This longer survival was also demonstrated in the Asia-Pacific phase III study ${ }^{(116,117)}$. Since then, sorafenib has been considered the first-line therapy for BCLC-C HCC.

Real-life studies later confirmed this benefit. Among these, the studies GIDEON ${ }^{(24)}$. and INSIGHT ${ }^{(246)}$ deserve to be highlighted. In the first study, 3,202 patients ( $73 \% \mathrm{CP} A$ and $25 \% \mathrm{CP} \mathrm{B})$ were analyzed. The incidence of side effects was similar in both groups, although severe side effects were more frequent in CP B patients (lower in those categorized as B7). The median survival rate was higher in CP A patients (13.6 months vs 5.2 months), when compared to CP B subjects. Although the average survival rate was lower in CP B7 patients (6.2 months), it was higher when compared to those categorized as CP B8, B9. The authors concluded that sorafenib may be used in selected CP B patients. Although the study showed better drug tolerance and benefit in CP B7 patients, there were some limitations, including the abscence of a control group.

The INSIGHT ${ }^{(246)}$ study was a prospective, non-interventional observational study conducted at 124 centers in Austria and Germany with 788 patients. About $50 \%$ of the patients had undergone some previous treatment, and most were stage BCLC C. The average overall survival was 15.1 months. The average survival according to BCLC (A: 29.2, B: 19.6, C: 13.6, D: 3.1 months) and according to $\mathrm{CP}(\mathrm{A}: 17.6, \mathrm{~B}: 8.1, \mathrm{C}: 5.6$ months) reinforces the fact that sorafenib was effective in real life, but once again CP A patients were those who benefited the most. Age did not affect prognosis, and adverse effects of any degree attributed to the drug occurred in $64.9 \%$ of patients, and they were more frequent in Child A patients.

When the survival rate and cost-effectiveness of sorafenib ${ }^{(247)}$ in patients with advanced HCC vs supportive care were assessed, the average survival rate with sorafenib was 150.5 days vs 62 days with best supportive care. Thus, sorafenib was found to be an independent prognostic factor for survival. The presence of advanced disease (decompensated cirrhosis) was considered to be an independent factor of poor prognosis. In decompensated disease, there was no cost-effective relationship.

In a systematic review and meta-analysis, in the treatment of advanced $\mathrm{HCC}^{(248)}$, analyzing 14 studies including sorafenib, TACE, TARE, ablation and no treatment, sorafenib was the only treatment that improved survival in CP A patients with advanced HCC.

The benefit of sorafenib in survival was also confirmed in a sub-analysis of several subgroups of patients with HCC, according to etiology of underlying disease, tumor burden, vascular invasion, metastasis, ECOG-PS, tumor stage, and previous treatment ${ }^{(249,250)}$. An analysis of the two databases of those phase III studies also revealed factors related to poor prognosis, including vascular invasion, high AFP and high neutrophil-to-lymphocyte ratio.
It is important to highlight the study that evaluated the role of the initial dose of sorafenib in the treatment of $\mathrm{HCC}^{(251)}$. In a prospective, multicenter, randomized study with a population of 4,903 patients, two regimens were proposed: full-dose sorafenib ( $800 \mathrm{mg} /$ day) vs an initial sorafenib dose of less than $800 \mathrm{mg} /$ day. After adjusting for potential confounders, there was no difference in overall survival (HRadj, $0.92 ; 95 \%$ CI, 0.83 to 1.01 ) with lower cost and fewer gastrointestinal side effects $(8.7 \%$ vs $10.8 \% ; P=0.047)$ in the reduced-dose group. Thus, the authors concluded that starting treatment at a lower dose does not lead to shorter survival, improves quality of life, and reduces costs.

Other proposals for the use of sorafenib were not successful in terms of survival improvement, as demonstrated in the STORM ${ }^{(252)}$ study (the use of sorafenib as adjuvant therapy after resection or ablation); or among studies in which sorafenib was used in patients who underwent TACE ${ }^{(189,191)}$. Regarding its use after transplantation, a systematic review and meta-analysis ${ }^{(253)}$ demonstrated survival benefit and safety in the use of sorafenib for $\mathrm{HCC}$ recurrence, but due to study heterogeneity, prospective controlled studies are still needed. This study raises concern for the use of sorafenib with mTOR inhibitors, as it may increase death for bleeding.

When we evaluated the national experience, with a series of 127 patients from two reference centers in the south and southeast regions $\left(85.6 \% \mathrm{CP}\right.$ A and 12\% B7) undergoing real-life treatment ${ }^{(254)}$, we observed a median survival of 19.9 months $(64.6 \%$ in 1 year; $26.6 \%$ in three years). The longer survival observed in this study, when compared to pivotal studies, is partly due to the fact that the treatment migration concept was used (18.1\% were BCLC-B). Side effects were observed in $97.6 \%$ of cases (mainly diarrhea and hand-foot syndrome). In South America, also evaluating 127 sorafenib-treated patients, the median survival rate was of 8 months (interquartile range 2 to 17). The shorter survival found in this real-life study is partly due to differences between the assessed populations ${ }^{(255)}$.

It should be noted that the FDA has recently approved Levantinib as a first-line treatment for HCC. Levantinib is an oral multikinase inhibitor with anti-angiogenic action. In an open-label, phase III, randomized, multicenter, non-inferiority trial, involving patients with advanced HCC (excluding patients with main portal vascular invasion and $>50 \%$ tumor total liver volume occupancy), levantinib showed noninferiority in overall survival when compared to sorafenib ${ }^{(118)}$. During the update of $\mathrm{SBH}$ recommendations for treatment of HCC meeting, the drug was not yet approved in Brazil, and due to this reason was not further discussed in the present manuscript.

\section{Second-line systemic therapy}

In the management of $\mathrm{HCC}$, it is appropriate to remind that the concept of treatment beyond progression ${ }^{(256)}$, with the current availability of new drugs and 2nd line treatment, if not abandoned, deserves at least more reflection. A 2nd-line treatment for HCC should be considered in the presence of drug intolerance or disease progression when using sorafenib. Until recently, no drug had shown benefit in the second line of HCC systemic therapy, despite numerous RCTs, making patients with HCC who progressed on sorafenib a challenge. In 2017, the FDA approved regorafenib as a second-line treatment for HCC. Regorafenib is a multikinase inhibitor that acts by blocking angiogenesis, proliferation, and tumor immunity. Because it has a broader action as a kinase inhibitor, the drug has a greater inhibitory potential than sorafenib ${ }^{(257)}$. The RES$\mathrm{ORCE}^{(119)}$ study was the first phase III second-line study of systemic 
therapy for patients with HCC that showed a positive result. This study included BCLC B or C, CP A patients who had radiological progression during sorafenib treatment and who tolerated a dose of sorafenib $\geq 400 \mathrm{mg} /$ day for at least 20 days within 28 days prior to discontinuation. A total of 573 patients were randomized (379 used $160 \mathrm{mg} /$ day regorafenib for three weeks of each four-week cycle and 194 patients used placebo). Regorafenib led to an increase in overall survival (10.6 vs 7.8 months in placebo group; $P<0.001)$.

Regarding the safety profile, the most common serious adverse events were hypertension, hand-foot syndrome (HFS), fatigue, and diarrhea, and these occurred more frequently in the regorafenib group. A retrospective analysis of the data from this study showed that patients with HFS tend to have better overall survival ${ }^{(257)}$. The drug was recently approved as a 2nd line therapy for HCC in Brazil.

A second phase III study was published in 2018 that also evaluated patients who progressed on sorafenib, comparing cabozantinib with placebo, with an increase in median overall survival in the group that used this drug (10.2 vs 8 months in placebo group, $P=0.005$ ). Ramucirumab is a monoclonal antibody that inhibits ligand activation of VEGFR2. In a recent publish study showed improved overall survival when compared with placebo in patients with $\mathrm{HCC}$ and AFP $\geq 400 \mathrm{ng} / \mathrm{mL}$ who had previously received sorafenib ${ }^{(258)}$. This drugs, as well as nivolumab ${ }^{(259)}$, were recently approved by the $\mathrm{FDA}^{(120)}$, but during the update of $\mathrm{SBH}$ recommendations for treatment of $\mathrm{HCC}$ meeting, those drugs were not yet approved in Brazil, and due to this reason were not further discussed in the present manuscript.

\section{Management of adverse events of systemic therapy}

Because sorafenib and regorafenib have very similar molecules, they have very similar adverse effects $(\mathrm{AE})^{(260,261)}$. The most frequent AE were dermatological and gastrointestinal ${ }^{(116,117,245)}$. Adverse effects should be classified as mild (grade I), moderate (grade II), or severe (grade III/IV). In case of mild reactions, symptomatic treatment without dose modification is recommended; in moderate reactions, the dose of sorafenib should be reduced; and in severe reactions, the medication should be temporarily discontinued. If AE disappear with sorafenib discontinuation, the relationship to medication is confirmed, and the adequate dose should be defined. If they do not disappear, disease progression, cirrhosis complications, or other causes should be excluded before assuming they are drug related ${ }^{(262,263)}$.

Adverse effects that most often impact the quality of life include HFS, rash, diarrhea, and fatigue. Hypertension frequently occurs, although it does not directly affect the quality of life ${ }^{(264)}$. These are early AE, which usually occur within the first two months of treatment ${ }^{(263)}$. Late AE, which occur after six months of treatment, include ischemia and peripheral vascular disease, which are related to the anti-angiogenic effect of sorafenib ${ }^{(263)}$.

Hand-foot syndrome usually appears within the first six weeks of treatment. It is recommended that the patient be evaluated fortnightly during the first two months of treatment to early manage this manifestation. Prophylactic use of $10 \%$ urea cream three times a day may reduce and postpone HFS incidence, and it may improve the quality of life of these patients ${ }^{(265)}$. Other recommended measures to prevent HFS are: wearing comfortable shoes, wearing cotton socks or gloves at night after applying moisturizer to maintain humidity, avoiding activities that promote excessive friction on hands and feet and avoiding hot water ${ }^{(260,264,266,267)}$. Some measures may be used in the symptomatic treatment of
HFS, although they are based solely on the recommendations of the authors, such as the use of clobetasol cream in erythematous areas, use of topical analgesic (e.g. $2 \%$ lidocaine) for pain, use of keratolytic agents such as $20 \%-40 \%$ urea or salicylic acid in callus, soak the feet in cold water with magnesium sulfate to soften calluses ${ }^{(264,266,268)}$.

Hand-foot syndrome is classified as mild (grade 1) when there is mild erythema or edema without pain; moderate (grade 2) when there is peeling, cracking, blistering or calluses without severe pain; or severe (grade 3), when there is ulcerative dermatitis or pain that makes walking or hand use difficult. In grade $1 \mathrm{HFS}$, there is no indication of sorafenib dose change. In grade $2 \mathrm{HFS}$, the symptomatic measures listed above can be used. If it does not improve, the sorafenib dose should be reduced by $50 \%$ for $7-28$ days, until improvement, when it may return to baseline; If it does not improve with the dose reduction, the medication should be discontinued and then restarted at half the daily dose (400 mg 1x/day). In grade 3 HFS, sorafenib should be discontinued for at least 7 days until clinical improvement, when it should be restarted at half dose. If no toxicity is present, the dose may be escalated to full dose. If it occurs again, maintain a dose of $400 \mathrm{mg} /$ day $^{(260,264)}$.

Diarrhea is often associated with treatment with these medications. It usually occurs early in the first two months of treatment. In cirrhotic patients, it may also be related to the use of lactulose to control hepatic encephalopathy, and dose adjustment of the latter may be necessary. Uncontrolled diarrhea can lead to dehydration and electrolyte imbalance, as well as the impact on the quality of life. Its treatment includes dietary adjustments (avoiding fiber-rich, fatty, or dairy foods), as well as symptomatic treatment with loperamide $2-4 \mathrm{mg}$ every 4 hours, with dose adjustment as needed ${ }^{(264,269)}$

Despite efforts in the prevention and management of AE, the occurrence of skin lesions, diarrhea, and hypertension are associated with longer survival, and it may act as clinical biomarkers of sorafenib efficacy in patients with HCC, especially dermatological reactions that occur in the first 60 days of treatment $t^{(262,270,271)}$.

\section{Recommendations}

- To date, treatment strategies based on conventional systemic chemotherapy have failed to show benefit, either in terms of survival or in reducing tumor time to progression (high level of evidence; weak recommendation).

- Sorafenib is indicated for patients with cirrhosis and advanced HCC, BCLC-C, but with preserved liver function (Child A). (high level of evidence; strong recommendation).

- Depending on the patient, the initial dose of sorafenib may be lower than conventional. (moderate level of evidence; strong recommendation).

- Eventually, sorafenib may be indicated in Child B patients with a score no greater than 7 (low level of evidence; weak recommendation).

- In the presence of tumor progression despite drug use, systemic rescue therapy should be considered (moderate level of evidence; strong recommendation).

- In cases where there is no response to locoregional therapy (or when it cannot be performed), therapeutic migration may be performed, and sorafenib may be started (moderate level of evidence; strong recommendation).

- Regorafenib is indicated in patients with HCC and CHILD A cirrhosis who have progressed on sorafenib but tolerated 
the medication well (moderate level of evidence; strong recommendation). There are no data to support the use of regorafenib in other situations (Child $\mathrm{B}$ or $\mathrm{C}$ or in patients who have not tolerated sorafenib).

- Patients using sorafenib or regorafenib should have easy access to health care staff for the early management of adverse effects. Biweekly reassessments are recommended in the first two months of treatment. Thereafter, appointments should be scheduled monthly. (moderate level of evidence; strong recommendation).

- In case of mild adverse effects, symptomatic treatment without dose modification is recommended; in moderate reactions, the dose of sorafenib should be reduced; and in severe reactions, medication should be temporarily discontinued (moderate level of evidence; strong recommendation).

\section{TERMINAL STAGE HCC - BCLC D}

This group includes patients who are not eligible for LT, with severe liver dysfunction and/or severely deteriorated physical condition, defined as ECOG-PS greater than $2^{(47,105)}$. At this stage, patients have a very poor prognosis, and, in the vast majority of cases, only supportive treatment (exclusive palliative care) is recommended $^{(47,105)}$.

According to the WHO, palliative care is an approach that promotes the quality of life of patients and families facing lifethreatening illnesses through prevention and alleviation of suffering, requiring early identification, evaluation, and adequate management of pain and of other problems, physical, psychosocial and spiritual ${ }^{(272)}$.

The American Society of Clinical Oncology recommends that patients with advanced malignancies be referred to the multidisciplinary palliative care team, from the beginning of the disease course. The main components of the approach are bonding with patient and family, managing symptoms and problems related to loss of functionality, understanding patient's awareness of the disease, and prognosis, clarifying care goals, assessing psychological needs and available resources for coping with the disease, decision-making assistance and care coordination ${ }^{(273)}$.

Pain is a frequent symptom as a consequence of liver involvement or metastatic injury. Patients with reduced liver function due to cirrhosis should receive analgesic medications taking into account the change in the metabolism of these drugs. The choice of medication should follow the WHO analgesic ladder principle. Mild pain (intensity $1-3$ ) may receive acetaminophen, with a dose of up to $3 \mathrm{~g} /$ day being safe. Moderate pain (intensity 4-6) indicates an association of a weak opioid, although its action might be unpredictable if liver function is impaired. Severe pain (7-10) indicates the use of strong opioids, most of which are metabolized by the liver and eliminated by the kidneys. Morphine is the most commonly used in our country, and care should be taken to reduce the dose and increase interval as liver function is impaired. Radiotherapy can be used to relieve pain in patients with bone metastases and also to control symptoms due to lung and/or lymph node metastases ${ }^{(274,275)}$.

Malnutrition in the advanced phase of the disease is common, and it has a multifactorial origin. There is no evidence to support the use of enteral or parenteral nutrition in this scenario ${ }^{(276)}$. Comfort should always be prioritized over the use of artificial feeding in this context.
Other prevalent symptoms that should be evaluated are cancerrelated anorexia/cachexia, fatigue, ascites, nausea and vomiting, pruritus, and constipation, not to mention the psychic, social, and spiritual aspects ${ }^{(274)}$.

Cohort studies indicate that patients with $\mathrm{HCC}$ who are at palliative care receive fewer invasive end-of-life measures, have more discussions about care goals, receive more care focused on comfort, and are more likely to die at home. No randomized controlled trials were found in this specific population ${ }^{(277)}$.

These findings suggest that the early approach of palliative care provides a reduction of suffering throughout cancer treatment and better quality of end-of-life care in patients with HCC.

\section{Recommendations}

- Patients with end-stage HCC should receive a palliative care approach by a multidisciplinary team, due to low survival rates and high prevalence of problems related to physical and mental symptoms (low level of evidence; strong recommendation).

\section{ACKNOWLEDGEMENTS}

The authors would like to express their deepest gratitude to all participants who contributed during the meeting to the development of this consensus: Dr. Edna Strauss, Dr. Isaac Altikes, Dr. Adriano Miziara Gonzales, Dr. Ivonete Sandra de Souza e Silva, Dr. Tiago Sevá Pereira, Dr. André Moreira de Assis, Dr. Rodrigo Sebba Aires, Dr. Rogério Camargo Pinheiro Alves.

\section{Orcid}

Aline Lopes Chagas: 0000-0002-7404-2540.

Angelo Alves de Mattos: 0000-0003-2417-9765.

Flair José Carrilho: 0000-0002-7682-3105.

Paulo Lisboa Bittencourt: 0000-0003-0883-4870.

Denise Cerqueira Paranaguá Vezozzo: 0000-0002-9606-4935.

Natally de Souza Maciel Rocha Horvat: 0000-0001-8849-5789.

Manoel de Souza Rocha: 0000-0002-4503-8374.

Venâncio Avancini Ferreira Alves: 0000-0001-5285-4460.

Gabriela Perdomo Coral: 0000-0003-4318-2871.

Mário Reis Álvares-da-Silva: 0000-0002-5001-246X.

Fabio Marinho do Rego Barros: 0000-0003-1446-7739.

Marcos Roberto de Menezes: 0000-0001-7231-2925.

Lucas Moretti Monsignore: 0000-0003-2345-4921.

Fabricio Ferreira Coelho: 0000-0002-5290-8286.

Renato Ferreira da Silva: 0000-0001-9652-6426.

Rita de Cássia Martins Alves Silva: 0000-0001-6302-0939.

Ilka de Fatima Santana Ferreira Boin: 0000-0002-1165-2149.

Luiz Augusto Carneiro d'Albuquerque: 0000-0001-7607-7168.

José Huygens Parente Garcia: 0000-0002-2869-2462.

Guilherme Eduardo Gonçalves Felga: 0000-0002-0676-4867.

Aírton Mota Moreira: 0000-0002-0649-2208.

Maria Ignez Freitas Melro Braghiroli: 0000-0001-6366-8786.

Paulo Marcelo Gehm Hoff: 0000-0002-0065-2194.

Vivianne Barretto de Mello: 0000-0001-9651-5161.

Mariana Fonseca Dottori: 0000-0002-7508-8807.

Tiago Pugliese Branco: 0000-0001-6605-0471.

Leonardo de Lucca Schiavon: 0000-0003-4340-6820.

Thaisa de Fátima Almeida Costa: 0000-0003-3263-5687. 
Chagas AL, Mattos AA, Carrilho FJ, Bittencourt PL, Membros do Painel do $2^{\circ}$ Consenso da Sociedade Brasileira de Hepatologia no Diagnóstico e Manejo do Carcinoma Hepatocelular. Atualização das recomendações da Sociedade Brasileira de Hepatologia para o diagnóstico e tratamento do carcinoma hepatocelular. Arq Gastroenterol. 2020;57(Suppl 1):1-20

RESUMO - O carcinoma hepatocelular (CHC) é uma das principais causas de mortalidade relacionada a câncer no Brasil e no mundo. A Sociedade Brasileira de Hepatologia (SBH) publicou em 2015 suas primeiras recomendações sobre a abordagem do CHC. Desde então, novas evidências sobre o diagnóstico e tratamento do $\mathrm{CHC}$ foram relatadas na literatura médica, levando a diretoria da SBH a promover uma reunião monotemática sobre câncer primário de fígado em agosto de 2018 com o intuito de atualizar as recomendações sobre o manejo da neoplasia. Um grupo de experts foi convidado para realizar uma revisão sistemática da literatura e apresentar uma atualização baseada em evidências científicas visando que pudesse nortear a prática clínica multidisciplinar do CHC. O texto resultante foi submetido a avaliação e aprovação de todos membros da SBH através de sua homepage. O documento atual é a versão final que contêm as recomendações atualizadas e revisadas da SBH.

DESCRITORES - Carcinoma hepatocelular, diagnóstico. Carcinoma hepatocelular, terapia. Neoplasias hepáticas. Sociedades Médicas. Brasil.

\section{REFERENCES}

1. Carrilho FJ, Mattos AA, Vianey AF, Vezozzo DC, Marinho F, Souto FJ, et al. Brazilian society of hepatology recommendations for the diagnosis and treatment of hepatocellular carcinoma. Arq Gastroenterol. 2015;52 (Suppl 1):2-14.

2. Guyatt GH, Oxman AD, Vist GE, Kunz R, Falck-Ytter Y, Alonso-Coello P, et al. GRADE: an emerging consensus on rating quality of evidence and strength of recommendations. BMJ. 2008;336:924-6.

3. Bray F, Ferlay J, Soerjomataram I, Siegel RL, Torre LA, Jemal A. Global cancer statistics 2018: GLOBOCAN estimates of incidence and mortality worldwide for 36 cancers in 185 countries. CA Cancer J Clin. 2018;68:394-424.

4. Akinyeniju T, Abera S, Ahmed M, Alam N, Alemayohu MA, Allen C, et al. The burden of primary liver cancer and underlying etiologies from 1990 to 2015 at the global, regional, and national level. JAMA Oncol. 2017;3:1683-91.

5. Carrilho FJ, Paranaguá-Vezozzo DC, Chagas AL, Alencar RSSM, da Fonseca LG. Epidemiology of Liver Cancer in Latin America: Current and Future Trends. Semin Liv Disease. 2019. doi: 10.1055/s-0039-3399561.

6. Nader LA, Mattos AA, Bastos GA. Burden of liver disease in Brazil. Liver Int 2014;34:844-9.

7. El-Serag HB. Epidemiology of viral hepatites and hepatocellular carcinoma. Gastroenterology. 2012;142:1264-73.

8. White DL, Thrift AP, Kanwal F, Davila J, El-Serag HB. Incidence of hepatocellular carcinoma in all 50 United States, from 2000 to 2012. Gastroenterology. 2017;152:812-20

9. Paranagua-Vezozzo DC, Ono SK, Alvarado-Mora MV, Farias AQ, Cunha-Silva M, França JI, et al. Epidemiology of HCC in Brazil: incidence and risk factors in a ten-year cohort. Ann Hepatol. 2014;13:386-93.

10. Carrilho FJ, Kikuchi L, Branco F, Goncalves CS, Mattos AA; Brazilian HCC Study Group. Clinical and epidemiological aspects of hepatocellular carcinoma in Brazil. Clinics. 2010;65:1285-90.

11. Fattovich G, Stronffolini T, Zagni I, Donato F. Hepatocellular carcinoma in cirrhosis: Incidence and Risk Factors. Gastroenterology. 2004;127:35-50.

12. Chen CJ, Yang HI, Su J, Jen CL, You SL, Lu SN, et al. REVEAL-HBV Study Group. Risk of hepatocellular carcinoma across a biological gradient of serum hepatitis B virus DNA level. JAMA. 2006;295:65-73.

13. Aleman S, Rahbin N, Weiland O, Davidsdottir L, Hedenstierna M, Rose N, et al. A risk for hepatocellular carcinoma persists long-term after sustained virologic response in patients with hepatites C-associated liver cirrhosis. Clin Infect Dis. 2013;57:230-6.

14. Liu Y, Wu F. Global burden of aflatoxin-induced hepatocellular carcinoma: a risk assessment. Environmental Health Perspectives. 2010;118:818-24.

15. Nogueira JA, Ono-Nita SK, Nita ME, de Souza MMT, do Carmo EP, Mello AS, et al. 249 TP53 mutation has high prevalence and is correlated with larger and poorly differentiated HCC in Brazilian patients. BMC Cancer. 2009 Jan; 9:204.

16. Gonçalves PL, Zago-Gomes Mda P, Gonçalves CS, Pereira FE. Hepatitis vírus and hepatocellular carcinoma in Brazil: a report from the State of Espirito Santo. Rev Soc Bras Med Trop. 2014; 47:559-63.

17. Wang P, Kang D, Cao W, Wang Y, Liu Z. Diabetes mellitus and risk of hepatocellular carcinoma: a systematic review and meta-analysis. Diabetes Metab Res Rev. 2012;28:109-22

18. Larsson SC, Wolk A. Overweight, obesity and risk of liver cancer: a meta-analysis of cohort studies. Br J Cancer. 2007; 97:1005-8.
19. Michelotti GA, Machado MV, Diehk AM. NAFLD, NASH and liver câncer. Nat Rev Gastroenterol Hepatol. 2013;10:656-65.

20. Chagas AL, Kikuchi LO, Oliveira CPMS, Vezozzo DCP, Mello ES, Oliveira $\mathrm{AC}$, et al. Does hepatocellular carcinoma in non-alcoholic steatohepatitis exist in cirrhotic and non-cirrhotic patients? Braz J Med Biol Res. 2009;42:958-62.

21. Cotrim HP, Oliveira CP, Coelho HS, Alvares-da-Silva MR, Nabuco L, Parise ER, et al. Nonalcoholic steatohepatitis and hepatocellular carcinoma: Brazilian survey. Clinics (Sao Paulo) 2016;71:281-4.

22. Fracanzani AL, Conte D, Fraquelli M, Taioli E, Mattioli M, Losco A, Fargion S. Increased cancer risk in a cohort of 230 patients with hereditary hemochromatosis in comparison to matched control patients with non-iron related chronic liver disease. Hepatology. 2001;33:647-51.

23. Chang MH, You SL, Chen CJ, Liu CJ, Lai MW, Wu TC, et al. Long-term effects of hepatitis B immunization of infants in preventing liver cancer. Gastroenterology. 2016:151:472-80

24. World Health Organization. Weekly epidemiological record. 2017;92:369-92.

25. Niederau C, Heintges T, Lange S, Goldmann G, Niederau CM, Mohr L, et al. Long-term follow-up of HBeAg-positive patients treated with interferon alfa for chronic hepatitis B. N Engl J Med. 1996;334:1422-7.

26. Papatheodoridis GV, Chan HL, Hansen BE, Janssen HL, Lampertico P. Risk of hepatocellular carcinoma in chronic hepatitis B: Assessment and modification with current antiviral therapy. J Hepatol, 2015;62:956-67.

27. Varbobitis I, Papatheodoridis GV. The assessment of hepatocellular carcinoma risk in patients with chronic hepatitis B under antiviral therapy. Clin Mol Hepatol. 2016;22:319-26

28. Papatheodoridis GV, Idilman R, Dalekos GN, Buti M, Chi H, van Boemmel $\mathrm{F}$, et al. The risk of hepatocellular carcinoma decreases after the first 5 years of entecavir or tenofovir in Caucasians with chronic hepatitis B. Hepatology. 2017;66:1444-53

29. Van der Meer AJ, Veldt BJ, Feld JJ, Wedemeyer H, Dufour JF, Lammert F, et al. Association between sustained virological response and all-cause mortality among patients with chronic hepatitis $\mathrm{C}$ and advanced hepatic fibrosis. JAMA. 2012;308:2584.

30. Colombo M, Iavarone M. Role of antiviral treatment for HCC prevention. Best Pract Res Clin Gastroenterol. 2014;28:771-81.

31. Morgan RL, Baack B, Smith BD, Yartel A, Pitasi M, Falck-Ytter Y. Eradication of hepatitis $\mathrm{C}$ virus infection and the development of hepatocellular carcinoma: a meta-analysis of observational studies. Ann Intern Med. 2013;158:329-37.

32. D'Ambrosio R, Della Corte C, Colombo M. Hepatocellular carcinoma in patients with a sustained response to anti-hepatitis C therapy. Int J Mol Sci. 2015;16:19698-712

33. Foster GR, Irving WL, Cheung MCM, Walker AJ, Hudson BE, Verma S, et al. Impact of direct acting antiviral therapy in patients with chronic hepatitis $\mathrm{C}$ and decompensated cirrhosis. J Hepatol. 2016;64:1224-31.

34. Reig M, Marino Z, Perello C, Inarrairaegui M, Ribeiro A, Lens S, et al. Unexpected high rate of early tumor recurrence in patients with $\mathrm{HCV}$ related $\mathrm{HCC}$ undergoing interferon-free therapy. J Hepatol. 2016;65:719-26.

35. Conti F, Buonfiglioli F, Scuteri A, Crespi C, Bolondi L, Caraceni P, et al. Early occurrence and recurrence of hepatocellular carcinoma in HCV related cirrhosis treated with direct-acting antivirals. J Hepatol. 2016;65:727-33. 
36. ANRS collaborative study group on hepatocellular carcinoma. Lack of evidence of an effect of direct-acting antivirals on the recurrence of hepatocellular carcinoma: Data from three ANRS cohorts. J Hepatol. 2016;65:734-40.

37. Sugimoto K, Kim SR, Kim SK, Imoto S, Tohyama M, Kim KI, et al. Comparison of daclatasvir and asunaprevir for chronic HCV $1 \mathrm{~b}$ infection with telaprevir and simeprevir plus peginterferon and ribavirin, with a focus on the prevention of occurrence and recurrence of hepatocellular carcinoma. Oncology. 2015; 89:42-6.

38. Kobayashi M, Suzuki F, Fujiyama S, Kawamura Y, Sezaki H, Hosaka T, et al. Sustained virologic response by direct antiviral agents reduces the incidence of hepatocellular carcinoma in patients with HCV infection. J Med Virol. 2017;89:476-83

39. Cabibbo G, Petta S, Calvaruso V, Cacciola I, Cannavo MR, Madonia S, et al. Is early recurrence of hepatocellular carcinoma in $\mathrm{HCV}$ cirrhotic patients affected by treatment with direct-acting antivirals? A prospective multicentre study. Aliment Pharmacol Ther. 2017;46:688-95.

40. Waziry R, Hajarizadeh B, Grebely J, Amin J, Law M, Danta M, et al. Hepatocellular carcinoma risk following direct-acting antiviral HCV therapy: A systematic review, meta-analyses, and meta-regression. J Hepatol. 2017;67:1204-12.

41. Kanwal F, Kramer J, Asch SM, Chayanupatkul M, Cao Y, El-Serag HB. Risk of hepatocellular cancer in HCV patients treated with direct-acting antiviral agents. Gastroenterology. 2017;153:996-1005.

42. Bravi F, Bosetti C, Tavani A, Bagnardi V, Gallus S, Negri E, et al. Coffee drinking and hepatocellular carcinoma risk: A meta-analysis. Hepatology. 2007:46:430-35.

43. Bravi F, Tavani A, Bosetti C, Boffetta P, La Vecchia C. Coffee and the risk of hepatocellular carcinoma and chronic liver disease: a systematic review and meta-analysis of prospective studies. Eur J Cancer Prev. 2017;26:368-77.

44. Kennedy OJ, Roderick P, Buchanan R, Fallowfield JA, Hayes PC, Parkes J. Coffee, including caffeinated and decaffeinated coffee, and the risk of hepatocellular carcinoma: a systematic review and dose-response meta-analysis. BMJ Open. 2017;7(5).

45. Setiawan VW, Wilkens LR, Lu SC, Hernandez BY, Le Marchand L, Henderson BE. Association of coffee intake with reduced incidence of liver cancer and death from chronic liver disease in the US multiethnic cohort. Gastroenterology. 2015;148:118-25

46. Sherman M, Colombo M. Hepatocellular carcinoma screening and diagnosis. Semin Liver Dis. 2014;34:389-97.

47. European Association for the Study of the Liver. EASL Clinical Practice Guidelines: Management of hepatocellular carcinoma. J Hepatol. 2018;69:182-236.

48. Parkin DM, Bray F, Ferlay J, Pisani P. Estimating the world cancer burden Globocan 2000. Int J Cancer. 2001;94:153-6.

49. Chen JG, Parkin DM, Chen QG, Lu JH, Shen QJ, Zhang BC, et al. Screening for liver cancer: results of a randomised controlled trial in Qidong, China. J Med Screen. 2003;10:204-9.

50. Zhang BH, Yang BH, Tang ZY. Randomized controlled trial of screening for hepatocellular carcinoma. J Cancer Res Clin Oncol. 2004;130:417-22.

51. Yang B, Zhang B, Xu Y, Wang W, Shen Y, Zhang A, et al. Prospective study of early detection for primary liver cancer. J Cancer Res Clin Oncol. 1997; 123:357-60

52. Trevisani F, Santi V, Gramenzi A, Di Nolfo MA, Del Poggio P, Benvegnù L, et al. Surveillance for early diagnosis of hepatocellular carcinoma: is it effective in intermediate/advanced cirrhosis? Am J Gastroenterol. 2007;102:2448-57.

53. Heimbach JK, Kulik LM, Finn RS, Sirlin CB, Abecassis MM, Roberts LR, et al. AASLD guidelines for the treatment of hepatocellular carcinoma. Hepatology. 2018;67:358-80

54. Barbara L, Benzi G, Gaiani S, Fusconi F, Zironi G, Siringo S, et al. Natural history of small untreated hepatocellular carcinoma in cirrhosis: a multivariate analysis of prognostic factors of tumor growth rate and patient survival. Hepatology. 1992;16:132-7.

55. Ebara M, Ohto M, Shinagawa T, Sugiura N, Kimura K, Matsutani S, et al. Natural history of minute hepatocellular carcinoma smaller than three centimeters complicating cirrhosis. A study in 22 patients. Gastroenterology. 1986;90:289-98.

56. Sheu JC, Sung JL, Chen DS, Yang PM, Lai MY, Lee CS, et al. Growth rate of asymptomatic hepatocellular carcinoma and its clinical implications. Gastroenterology. 1985;89:259-66.

57. Makuuchi M, Kokudo N, Arii S, Futagawa S, Kaneko S, Kawasaki S, et al. Development of evidence-based clinical guidelines for the diagnosis and treatment of hepatocellular carcinoma in Japan. Hepatol Res. 2008;38:37-51.

58. Trinchet JC, Chaffaut C, Bourcier V, Degos F, Henrion J, Fontaine H, et al. Ultrasonographic surveillance of hepatocellular carcinoma in cirrhosis: a randomized trial comparing 3- and 6-month periodicities. Hepatology. 2011;54:1987-97.

59. Santagostino E, Colombo M, Rivi M, Rumi MG, Rocino A, Linari S, et al. A 6 month versus a 12-month surveillance for hepatocellular carcinoma in 559 hemophiliacs infected with the hepatitis C virus. Blood. 2003;102:78-82.
60. Thompson Coon J, Rogers G, Hewson P, Wright D, Anderson R, Cramp M, et al. Surveillance of cirrhosis for hepatocellular carcinoma: systematic review and economic analysis. Health Technol Assess. 2007;11:1-206.

61. Laupacis A, Feeny D, Detsky AS, Tugwell PX. How attractive does a new technology have to be to warrant adoption and utilization? Tentative guidelines for using clinical and economic evaluations. CMAJ. 1992;146:473-81.

62. Sarasin FP, Giostra E, Hadengue A. Cost-effectiveness of screening for detection of small hepatocellular carcinoma in western patients with Child-Pugh class A cirrhosis. Am J Med. 1996;101:422-34.

63. Andersson KL, Salomon JA, Goldie SJ, Chung RT. Cost effectiveness of alternative surveillance strategies for hepatocellular carcinoma in patients with cirrhosis. Clin Gastroenterol Hepatol. 2008;6:1418-24.

64. Yang HI, Yuen MF, Chan HL, Han KH, Chen PJ, Kim DY, et al. Risk estimation for hepatocellular carcinoma in chronic hepatitis B (REACH-B): development and validation of a predictive score. Lancet Oncol. 2011;12:568-74

65. Papatheodoridis G, Dalekos G, Sypsa V, Yurdaydin C, Buti M, Goulis J, et al PAGE-B predicts the risk of developing hepatocellular carcinoma in Caucasians with chronic hepatitis B on 5-year antiviral therapy. J Hepatol. 2016;64:800-6.

66. Degasperi E, Colombo M. Distinctive features of hepatocellular carcinoma in non-alcoholic fatty liver disease. Lancet Gastroenterol Hepatol. 2016;1:156-64

67. Piscaglia F, Svegliati-Baroni G, Barchetti A, Pecorelli A, Marinelli S, Tiribelli $\mathrm{C}$, et al. Clinical patterns of hepatocellular carcinoma in nonalcoholic fatty liver disease: A multicenter prospective study. Hepatology. 2016;63:827-38.

68. Paradis V, Zalinski S, Chelbi E, Guedj N, Degos F, Vilgrain V, et al. Hepatocellular carcinomas in patients with metabolic syndrome often develop without significant liver fibrosis: a pathological analysis. Hepatology. 2009;49:851-9.

69. Makarova-Rusher OV, Altekruse SF, McNeel TS, Ulahannan S, Duffy AG, Graubard BI, et al. Population attributable fractions of risk factors for hepatocellular carcinoma in the United States. Cancer. 2016;122:1757-65.

70. Singal A, Volk ML, Waljee A, Salgia R, Higgins P, Rogers MA, et al. Metaanalysis surveillance with ultrasound for early-stage hepatocellular carcinoma in patient with cirrhosis. Aliment Pharmacol Ther. 2009;30:37-47.

71. Davenport MS, Viglianti BL, Al-Hawary MM, Caoili EM, Kaza RK, Liu PS, et al. Comparison of acute transient dyspnea after intravenous administration of gadoxetate disodium and gadobenate dimeglumine: effect on arterial phase image quality. Radiology. 2013;266:452-61.

72. Manini MA, Sangiovanni A, Fornari F, Piscaglia F, Biolato M, Fanigliulo L, et al. Clinical and economical impact of 2010 AASLD guidelines for the diagnosis of hepatocellular carcinoma. J Hepatol. 2014;60:995-1001

73. Kojiro M. Pathological diagnosis at early stage: reaching international consensus Oncology. 2010;78 Suppl 1:31-5.

74. Roberts LR, Sirlin CB, Zaiem F, Almasri J, Prokop LJ, Heimbach JK, et al. Imaging for the Diagnosis of Hepatocellular Carcinoma: A Systematic Review and Meta-analysis Hepatology. 2018;67:401-21.

75. Lee YJ, Lee JM, Lee JS, Lee HY, Park BH, Kim YH, et al. Hepatocellular carcinoma: diagnostic performance of multidetector CT and MR imaging-a systematic review and meta-analysis. Radiology. 2015;275:97-109.

76. Duncan JK, Ma N, Vreugdenburg TD, Cameron AL, Maddern G. Gadoxetic acid-enhanced MRI for the characterization of hepatocellular. carcinoma: A systematic review and meta-analysis. J Magn Reson Imaging. 2017;45:281-290.

77. Guo J, Seo Y, Ren S, Hong S, Lee D, Kim S, et al. Diagnostic performance of contrast-enhanced multidetector computed tomography and gadoxetic acid disodium-enhanced magnetic resonance imaging in detecting hepatocellular carcinoma: direct comparison and a meta-analysis. Abdom Radiol. 2016;41:1960-72.

78. Pahade JK, Juice D, Staib L, Israel G, Cornfeld D, Mitchell K, et al. Is there an added value of a hepatobiliary phase with gadoxetate disodium following conventional MRI with an extracellular gadolinium agent in a single imaging session for detection of primary hepatic malignancies? Abdom Radiol. 2016;41: $1270-84$

79. Elsayes KM, Kielar AZ, Elmohr MM, Chernyak V, Masch WR, Furlan A, et al White paper of the Society of Abdominal Radiology hepatocellular carcinoma diagnosis disease-focused panel on LI-RADS v2018 for CT and MRI. Abdom Radiol. 2018;43:2625-42

80. LI-RADS 2018 CT MRI Core Portuguese - American College of Radiology (ACR). 2018. [Internet]. Available from: https://www.acr.org/-/media/ACR/ Files/RADS/LI-RADS/Translations/LI-RADS-2018-CT-MRI-Core-Portuguese pdf?la=en.

81. Elsayes KM, Kielar AZ, Chernyak V, Morshid A, Furlan A, Masch WR, et al LI-RADS: a conceptual and historical review from its beginning to its recent integration into AASLD clinical practice guidance. J Hepatocell Carcinoma. 2019;6:49-69.

82. The International Consensus Group for Hepatocellular Neoplasia. Pathologic diagnosis of early hepatocellular carcinoma: a report of the international consensus group for hepatocellular neoplasia. Hepatology. 2009;49:658-64 
83. Di Tommaso L, Destro A, Seok JY, Balladore E, Terracciano L, Sangiovanni A, et al. The application of markers (HSP70 GPC3 and GS) in liver biopsies is useful for detection of hepatocellular carcinoma. J Hepatol. 2009;50:746-54.

84. Tommaso L, Roncalli M. Tissue Biomarkers in Hepatocellular Tumors: Which, When, and How. Front Med (Lausanne). 2017:4:10.

85. Di Tommaso L, Destro A, Fabbris V, Spagnuolo G, Laura Fracanzani A, Fargion $\mathrm{S}$, et al. Diagnostic accuracy of clathrin heavy chain staining in a marker panel for the diagnosis of small hepatocellular carcinoma. Hepatology. 2011:53:1549-57.

86. Martins-Filho SN, Paiva C, Azevedo RS, Alves VAF. Histological Grading of Hepatocellular Carcinoma. A Systematic Review of Literature. Front Med (Lausanne). 2017;10;4:193.

87. Graham RP, Yeh MM, Lam-Himlin D, Roberts LR, Terracciano L, Cruise MW, et al. Molecular testing for the clinical diagnosis of fibrolamellar carcinoma. Mod Pathol. 2018;31:141-9.

88. Kim YJ, Rhee H, Yoo JE, Alves VAF, Kim GJ, Kim HM, et al. Tumour epithelial and stromal characteristics of hepatocellular carcinomas with abundant fibrous stroma: fibrolamellar versus scirrhous hepatocellular carcinoma. Histopathology. 2017;71:217-26.

89. Alves VA, D'Albuquerque LA. Nonalcoholic Steatohepatitis and Hepatocellular Carcinoma: Brazilian Survey. Clinics (Sao Paulo). 2016;71:423-4.

90. Calderaro J, Couchy G, Imbeaud S, Amaddeo G, Letouzé E, Blanc JF, et al. Histological subtypes of hepatocellular carcinoma are related to gene mutations and molecular tumour classification. J Hepatol. 2017;67:727-38.

91. Felipe-Silva A, Wakamatsu A, Dos Santos Cirqueira C, Alves VA. Immunohistochemistry panel segregates molecular types of hepatocellular carcinoma in Brazilian autopsy cases. World J Gastroenterol. 2016;22:6246-56.

92. Shimada S, Mogushi K, Akiyama Y, Furuyama T, Watanabe S, Ogura T, Ogawa K, Ono H, Mitsunori Y, Ban D, Kudo A, Arii S, Tanabe M, Wands JR, Tanaka S. Comprehensive molecular and immunological characterization of hepatocellular carcinoma. EBioMedicine. 2019;40:457-70.

93. Mullhaupt B, Durand F, Roskams T, Dutkowski P, Heim M. Is tumor biopsy necessary? Liver Transplant 2011;17(Suppl 2):S14-25.

94. Torbenson M, Schirmacher P. Liver cancer biopsy. Back to the future? Hepatology. 2015;61:431-3.

95. Wiesner RH, Freeman RB, Mulligan DC. Liver transplantation for hepatocellular cancer: the impact of the MELD allocation policy. Gastroenterology. 2004;127(Suppl 1):S261-7.

96. Compagnon P, Grandadam S, Lorho R, Turlin B, Camus C, Jianrong Y, et al. Liver transplantation for hepatocellular carcinoma without preoperative tumor biopsy. Transplantation. 2008;86:1068-76.

97. Silva MA, Hegab B, Hyde C, Guo B, Buckels JA, Mirza DF. Needle track seeding following biopsy of liver lesions in the diagnosis of hepatocellular cancer: a systematic review and meta-analysis. Gut. 2008;57:1592-6.

98. Forner A, Ayuso C, Isabel Real M, Sastre J, Robles R, Sangro B, et al. Diagnosis and treatment of hepatocellular carcinoma. Med Clin (Barc). 2009 28;132:272-87.

99. Blechacz B, Mishra L. Biopsy for liver cancer: How to balance research needs with evidence-based clinical practice. Hepatology. 2015;62:1645.

100. West J, Card TR. Reduced mortality rates following elective percutaneous liver biopsies. Gastroenterology. 2010;139:1230-7

101. Cardinale V, Semeraro R, Torrice A, Gatto M, Napoli C, Bragazzi MC, et al. Intra-hepatic and extra-hepatic cholangiocarcinoma: New insight into epidemiology and risk factors. World J Gastrointest Oncol. 2010;11:407-16.

102. Russo FP, Imondi A, Lynch EN, Farinati F. When and how should we perform a biopsy for $\mathrm{HCC}$ in patients with liver cirrhosis in 2018? A review. Digest Liver Dis. 2018; 640-6.

103. Llovet JM, Burroughs A, Bruix J. Hepatocellular carcinoma. Lancet. 2003;362:1907-17

104. Bruix J, Reig M, Sherman M. Evidence-based diagnosis, staging, and treatment of patients with hepatocellular carcinoma. Gastroenterology. 2016;150:835-53.

105. Forner A, Reig M, Bruix J. Hepatocellular Carcinoma. Lancet. 2018;391:1301-14.

106. Forner A, Díaz-González A, Liccioni A, Vilana R. Prognosis prediction and staging. Best Pract Res Clin Gastroenterol. 2014; 28:855-65.

107. Kikuchi L, Chagas AL, Alencar RSSM, Tani C, Diniz MA, D’Albuquerque LAC, et al. Adherence to BCLC recommendations for the treatment of hepatocellular carcinoma: impact on survival according to stage. Clinics (Sao Paulo). 2017;72:454-60.

108. Amim MB, Edge SB, American Joint Committee on Cancer. AJCC Cancer Staging Manual. 8th ed, NY: Springer, 2017.

109. A new prognostic system for hepatocellular carcinoma: a retrospective study of 435 patients: the Cancer of the Liver Italian Program (CLIP) investigators. Hepatology. 1998;28:751-5

110. Yau T, Tang VY, Yao TJ, Fan ST, Lo CM, Poon RT. Development of Hong Kong Liver Cancer staging system with treatment stratification for patients with hepatocellular carcinoma. Gastroenterology. 2014;146:1691-700.
111. Kitai S, Kudo M, Minami Y, Haji S, Osaki Y, Oka H, et al. Validation of a New Prognostic Staging System for Hepatocellular Carcinoma: A Comparison of the Biomarker-Combined Japan Integrated Staging Score, the Conventional Japan Integrated Staging Score and the BALAD Score. Oncology. 2008;75 (Suppl 1):83-90.

112. Liccioni A, Reig M, Bruix J. Treatment of hepatocellular carcinoma. Dig Dis. 2014;32:554-63

113. Bruix J, Castells A, Bosch J, Feu F, Fuster J, Garcia-Pagan JC, et al. Surgical resection of hepatocellular carcinoma in cirrhotic patients: prognostic value of preoperative portal pressure. Gastroenterology. 1996;111:1018-22.

114. Lencioni R. Loco-regional treatment of hepatocellular carcinoma. Hepatology. 2010; 52:762-73.

115. Forner A, Gilabert M, Bruix J, Raoul JL. Treatment of intermediate-stage hepatocellular carcinoma. Nat Rev Clin Oncol. 2014;11:525-35.

116. Llovet JM, Ricci S, Mazzaferro V, Hilgard P, Gane E, Blanc J-F, et al; SHARP Investigators Study Group. Sorafenib in advanced hepatocellular carcinoma. N Engl J Med. 2008;359:378-90.

117. Cheng AL, Kang YK, Chen Z, Tsao CJ, Qin S, Kim JS, et al. Efficacy and safety of sorafenib in patients in the Asia-Pacific region with advanced hepatocellular carcinoma: a phase III randomised, double-blind, placebo-controlled trial. Lancet Oncol. 2009;10:25-34.

118. Kudo M, Finn RS, Qin S, Han K-H, Ikeda K, Piscaglia F, et al. Lenvatinib vs. sorafenib in first-line treatment of patients with unresectable hepatocellular carcinoma: a randomised phase 3 non-inferiority trial. Lancet. 2018;391: 1163-73

119. Bruix J, Qin S, Merle P, Granito A, Huang Y-H, Bodoky G, et al. Regorafenib for patients with hepatocellular carcinoma who progressed on sorafenib treatment (RESORCE): a randomised, doubleblind, placebo-controlled, phase 3 trial. Lancet. 2017;7;389:56-66.

120. Abou-Alfa GK, Meyer T, Cheng AL, El-Khoueiry AB, Rimassa L, et al. Cabozantinib in Patients with Advanced and Progressing Hepatocellular Carcinoma. N Engl J Med. 2018;379:54-63.

121. Lencioni R, Crocetti L. Local-regional treatment of hepatocellular carcinoma. Radiology. 2012;262:43-58.

122. McDermott S, Gervais DA. Radiofrequency ablation of liver tumors. Semin Intervent Radiol. 2013;30:49-55.

123. Ansari D, Andersson R. Radiofrequency ablation or percutaneous ethanol injection for the treatment of liver tumors. World J Gastroenterol. 2012;18:1003-8.

124. Germani G, Pleguezuelo M, Gurusamy K, Meyer T, Isgrò G, Burroughs AK. Clinical outcomes of radiofrequency ablation, percutaneous alcohol and acetic acid injection for hepatocelullar carcinoma: A meta-analysis. J Hepatol. 2010; 52:380-8.

125. Cho YK, Kim JK, Kim MY, Rhim H, Han JK. Systematic review of randomized trials for hepatocellular carcinoma treated with percutaneous ablation therapies. Hepatology. 2009;49:453-9.

126. Orlando A, Leandro G, Olivo M, Andriulli A, Cottone M. Radiofrequency thermal ablation vs. percutaneous ethanol injection for small hepatocellular carcinoma in cirrhosis: meta-analysis of randomized controlled trials. American J Gastroenterol. 2009;104:514-24

127. Yang B, Zan RY, Wang SY, Li XL, Wei ML, Guo WH, et al. Radiofrequency ablation versus percutaneous ethanol injection for hepatocellular carcinoma: a meta-analysis of randomized controlled trials. World J Surg Oncol, 2015;13:96.

128. Livraghi T, Giorgio A, Marin G, Salmi A, de Sio I, Bolondi L, et al. Hepatocellular carcinoma and cirrhosis in 746 patients: long-term results of percutaneous ethanol injection. Radiology. 1995;197:101-8

129. Nault JC, Sutter O, Nahon P, Ganne-Carrie N, Seror O. Percutaneous treatment of hepatocellular carcinoma: State of the art and innovations. J Hepatol. 2018;68:783-97.

130. Gardini AC, Marisi G, Canale M, Foschi FG, Donati G, Ercolani G, et al. Radiofrequency ablation of hepatocellular carcinoma: a meta-analysis of overall survival and recurrence-free survival. OncoTargets Ther. 2018;11:6555-67.

131. Kikuchi L, Menezes M, Chagas AL, Tani CM, Alencar RS, Diniz MA, et al. Percutaneous radiofrequency ablation for early hepatocellular carcinoma: risk factors for survival. World J Gastroenterol. 2014;20:1585-93.

132. Luo W, Zhang Y, He G, et al. Effects of radiofrequency ablation versus other ablating techniques on hepatocellular carcinomas: a systematic review and meta-analysis. World J Surg Oncol. 2017;15:126.

133. Majumdar A, Roccarina D, Thorburn D, Davidson BR, Tsochatzis E, Gurusamy KS. Management of people with early- or very early-stage hepatocellular carcinoma: an attempted network meta-analysis. Cochrane Database Syst Rev. 2017;3:CD011650.

134. Cucchetti A, Piscaglia F, Cescon M, Colecchia A, Ercolani G, Bolondi L, et al. Cost-effectiveness of hepatic resection versus percutaneous radiofrequency ablation for early hepatocellular carcinoma. J Hepatol. 2013;59:300-7. 
135. Lee DH, Lee JM, Lee JY, Kim SH, Yoon JH, Kim YJ, et al. Radiofrequency Ab lation of Hepatocellular Carcinoma as First-Line Treatment: Long-term Results and Prognostic Factors in 162 Patients with Cirrhosis. Radiology. 2014;270:900-9.

136. Mazzaferro V, Regalia E, Doci R, Andreola S, Pulvirenti A, Bozzetti F, et al. Liver transplantation for the treatment of small hepatocellular carcinomas in patients with cirrhosis. N Engl J Med. 1996;334:693-9.

137. Pelletier SJ, Fu S, Thyagarajan V, Romero-Marrero C, Batheja MJ, Punch JD, Magee JC, et al. An intention-to treat analysis of liver transplantation for hepatocellular carcinoma using organ procurement transplant network data. Liver Transpl. 2009;15:859-68.

138. Fan ST, Mau Lo C, Poon RT, Yeung C, Leung Liu C, Yuen WK, et al. Continuous improvement of survival outcomes of resection of hepatocellular carcinoma: a 20-year experience. Ann Surg. 2011;253:745-58

139. Kudo M, Matsui O, Izumi N, Iijima H, Kadoya M; Liver Cancer Study Group of Japan. JSH consensus-based clinical practice guidelines for the managemnte of hepatocellular carcinoma 2014 update by the Liver Cancer Study Group of Japan. Liver Cancer. 2014;3:458-68.

140. Belghiti J, Fuks D. Liver resection and transplantation in hepatocellular carcinoma. Liver Cancer. 2012;1:71-82

141. Herman P, Lopes Fde L, Kruger JA, Fonseca GM, Jeismann VB, Coelho FF. Is resection of hepatocelular carcinoma in the era of liver transplantation worthwhile? A single center experience. Arq Gastroenterol. 2016;53:169-74.

142. Chang WT, Kao WY, Chau GY, Su CW, Lei HJ, Wu JC, et al. Hepatic resection can provide long-term survival of patients with non-early-stage hepatocellular carcinoma: extending the indication for resection? Surgery. 2012;152:809-20

143. Portolani N, Coniglio A, Ghidoni S, Giovanelli M, Benetti A, Tiberio GA, et al. Early and late recurrence after liver resection for hepatocellular carcinoma: prognostic and therapeutic implications. Ann Surg. 2006;243:229-35.

144. Llovet JM, Fuster J, Bruix J. Intention-to-treat analysis of surgical treatment for early hepatocellular carcinoma: resection versus transplantation. Hepatology. 1999;30:1434-40.

145. Berzigotti A, Reig M, Abraldes JG, Bosch J, Bruix J. Portal hypertension and the outcome of surgery for hepatocellular carcinoma in compensated cirrhosis a systematic review and meta-analysis. Hepatology 2015;61:526-36.

146. Cherqui D, Laurent A, Mocellin N, Tayar C, Luciani A, Van Nhieu JT, Decaens $\mathrm{T}$, et al. Liver resection for transplantable hepatocellular carcinoma: Long-term survival and role of secondary liver transplantation. Ann Surg. 2009;250:738-46

147. Guglielmi A, Ruzzenente A, Conci S, Valdegamberi A, Iacono C. How much remnant is enough in liver resection? Dig. Surg. 2012;29:6-17.

148. Kamath PS, Wiesner RH, Malinchoc M, Kremers W, Therneau TM, Kosberg $\mathrm{CL}$, et al. A model to predict survival in patients with end-stage liver disease. Hepatology. 2001;33:464-70.

149. Vitale A, Huo TL, Cucchetti A, Lee YH, Volk M, Frigo AC, et al. Survival benefit of liver transplantation versus resection for hepatocellular carcinoma: impact of MELD score. Ann Surg Oncol. 2015;22:1901-7.

150. Teh SH, Christein J, Donohue J, Que F, Kendrick M, Farnell M, et al. Hepatic resection of hepatocellular carcinoma in patients with cirrhosis: Model of EndStage Liver Disease (MELD) score predicts perioperative mortality. J Gastrointest Surg. 2005;9:1207-15.

151. Herman P, Perini MV, Coelho FF, Kruger JAP, Lupinacci RM, Fonseca GM, et al. Laparoscopic Resection of Hepatocellular carcinoma: When, Why, and How? A Single-Center Experience. J Laparoendoscop Adv Tech. 2014;24:223-8.

152. Soubrane O, Goumard C, Laurent A, Tranchart H, Truant S, Gayet B, et al Laparoscopic resection of hepatocellular carcinoma: A French survey in 351 patients. HPB (Oxford). 2014; 16:357-65.

153. Coelho FF, Kruger JA, Fonseca GM, Araujo RL, Jeismann VB, Perini MV, et al. Laparoscopic liver resection: Experience based guidelines. World J Gastrointes Surg. 2016;8:5-26

154. Associação Brasileira de Transplantes de Órgãos (ABTO). Dimensionamento dos Transplantes no Brasil e em cada Estado (2008-2015). Registro Brasileiro de Transplantes, 2015; ano XXI, n ${ }^{\circ} 4$

155. Adam R, Karam V, Delvart V, O’Grady J, Mirza D, Klempnauer J, et al Evolution of indications and results of liver transplantation in Europe. A report from the European Liver Transplant Registry (ELTR). J Hepatol. 2012;57:675-88.

156. Figueras J, Jaurrieta E, Valis C, Benasco C, Rafecas A, Xiol X, et al. Survival after liver transplantation in cirrhotic patients with and without Hepatocellular carcinoma: a comparative study. Hepatology. 1997;25:1485-9.

157. Llovet JM, Bruix J, Fuster J, Castells A, Garcia-Valdecasas JC, Grande L, et al Liver transplantation for small hepatocellular carcinoma: the tumor-node-metastasis classification does not have prognostic power. Hepatology. 1998;27:1572-7.

158. Sapisochin G, Bruix J. Liver transplantation for hepatocellular carcinoma outcomes and novel surgical approaches. Nat Rev Gastroenterol Hepatol. 2017;14,203-17.

159. European Liver Transplant Registry. 2016. www.eltr.org. Accessed 25 April 2017.
160. Yang JD, Larson JJ, Watt KD, Allen AM, Wiesner RH, Gores GJ, et al. Hepatocellular carcinoma is the most common indication for liver transplantation and placement on the waitlist in the United States. Clin Gastroenterol Hepatol. 2017; $15: 767-75$

161. Bittencourt PL, Farias AQ, Couto CA. Liver transplantation in Brazil. Liver Transpl. 2016;22:1254-8.

162. Bhorri S, Mazzaferro V. Current challenges in liver transplantation for hepatocellular carcinoma. Best Pract Res Clin Gastroenterol. 2014;28:867-79.

163. United Network for Organ Sharing. Available from: https://www.unos.org/policy/ policy-development.

164. Mazzaferro V, Bhoori S, Sposito C, Bongini M, Langer M, Miceli R, et al. Milan criteria in liver transplantation for hepatocellular carcinoma: an evidence based analysis of 15 years of experience. Liver Transpl. 2011;17 (Suppl 2):S44-57.

165. Mancuso A, Perricone G. Hepatocellular carcinoma and liver transplantation: State of the art. J Clin Transl Hepatol. 2014;2:176-81.

166. Fahrner R, Dondorf F, Ardelt M, Dittmar Yves, Settmacher U, Rauchfuß F. Liver transplantation for hepatocellular carcinoma: Factors influencing outcome and disease-free survival. World J Gastroenterol. 2015;21:12071-82.

167. Herrero JI, Sangro B, Pardo F, Quiroga J, Iñarrairaegui M, Rotellar F, et al. Liver transplantation in patients with hepatocellular carcinoma across Milan criteria. Liver Transpl. 2008;14:272-78.

168. Yao FY, Ferrell L, Bass NM, Watson JJ, Bacchetti P, Venook A, Ascher NL, Roberts JP. Liver transplantation for hepatocellular carcinoma: expansion of the tumor size limits does not adversely impact survival. Hepatology. 2001;33:1394-403.

169. Mazzaferro V, Llovet JM, Miceli R, Bhoori S, Schiavo M, Mariani L, et al Metroticket Investigator Study Group. Predicting survival after liver transplantation in patients with hepatocellular carcinoma beyond the Milan criteria: a retrospective, exploratory analysis. Lancet. 2009;10:35-43.

170. Takada Y, Uemoto S. Liver transplantation for hepatocellular carcinoma: the Kyoto experience. J Hepatobiliary Pancreat Sci. 2010;17:527-32.

171. Fan J, Zhou J, Xu Y, Qiu SJ, Wu ZQ, Yu Y, et al. Indication of liver transplantation for hepatocellular carcinoma: Shanghai Fudan Criteria. Zhonghua Yi Xue Za Zhi. 2006;86:1227-31

172. Zheng SS, Xu X, Wu J, Chen J, Wang WL, Zhang M, et al Liver transplantation for hepatocellular carcinoma: Hangzhou experiences. Transplantation. 2008;85:1726-32.

173. DuBay D, Sandroussi C, Sandhu L, Cleary S, Guba M, Cattral MS, et al. Liver transplantation for advanced hepatocellular carcinoma using poor tumor differentiation on biopsy as an exclusion criterion. Ann Surg. 2011;253:166-72.

174. Duvoux C, Roudot-Thoraval F, Decaens T, Pessione F, Badran H, Piardi T, et al; Liver Transplantation French Study Group. Liver transplantation for hepatocellular carcinoma: a model including $\bigotimes$-fetoprotein improves the performance of Milan criteria. Gastroenterology. 2012;143:986-94.e3; quiz e14-5.

175. Guerrero-Misas M, Rodríguez-Perálvarez M, la Mata MD. Strategies to improve outcome of patients with hepatocellular carcinoma receiving a liver transplantation. World J Hepatol. 2015;7:649-61.

176. Lencioni R, Llovet JM. Modified RECIST (mRECIST) assessment for hepatocellular carcinoma. Semin Liver Dis. 2010;30:52-60.

177. Soriano A, Varona A, Gianchandani R, Moneva M, Arranz J, Gonzalez A, et al. Selection of patients with hepatocellular carcinoma for liver transplantation: Past and future. World J Hepatol. 2016;8:58-68.

178. Brasil. Ministério da Saúde Gabinete do Ministro. Portaria no 1.160, de 29 de maio de 2006

179. Chagas AL. Avaliação da recidiva do carcinoma hepatocelular em pacientes submetidos a transplante de fígado no Brasil. Tese apresentada a Universidade de São Paulo para obtenção de título de Doutora em Ciências. SP, 2017.www. teses.usp.br/teses/disponiveis/5/5168/tde30012018.../AlineLopesChagas.pdf.

180. Liapi E, Geschwind JF. Intraarterial therapies for hepatocellular carcinoma: Where do we stand? Ann Surg Oncol. 2010;17:123446.

181. Melchiorre F, Patella F, Pescatori L, Pesapane F, Fumarola E, Biondetti P, et al DEB-TACE: a standard review. Future Oncology. 2018;14:2969-84.

182. Sacco R, Mismas V, Marceglia S, Romano A, Giacomelli L, Bertini M, et al Transarterial radioembolization for hepatocellular carcinoma: An update and perspectives. World J Gastroenterol. 2015;21:6518-25.

183. Llovet JM, Bruix J. Systematic review of randomized trials for unresectable hepatocellular carcinoma: Chemoembolization improves survival. Hepatology 2003;37:429-42.

184. Facciorusso A, Di Maso M, Muscatiello N. Drug-eluting beads versus conventional chemoembolization for the treatment of unresectable hepatocellular carcinoma: A meta-analysis. Digest Liver Dis. 2016;48:571-7.

185. Lammer J, Malagari K, Vogl T, Pilleul F, Denys A, Watkinson A, et al. Prospective randomized study of doxorubicin-eluting-bead embolization in the treatmen of hepatocellular carcinoma: results of the PRECISION V study. Cardiovase Intervent Radiol. 2010;33:41-52. 
186. Golfieri R, Giampalma E, Renzulli M, Cioni R, Bargellini I, Bartolozzi C, et al. Randomised controlled trial of doxorubicin-eluting beads vs. conventional chemoembolisation for hepatocellular carcinoma. British J Cancer. 2014;111: 255-64.

187. Lee YK, Jung KS, Kim DY, Choi JY, Kim BK, Kim SU, et al. Conventional versus drug-eluting beads chemoembolization for hepatocellular carcinoma: Emphasis on the impact of tumor size. J Gastroenterol Hepatol. 2017;32:487-96.

188. Chen QW, Ying HF, Gao S, Shen YH, Meng ZQ, Chen H, et al. Radiofrequency ablation plus chemoembolization versus radiofrequency ablation alone for hepatocellular carcinoma: a systematic review and meta-analysis. Clin Res Hepatol Gastroenterol. 2016; 40:309-14

189. Lencioni R, Llovet JM, Han G, Tak WY4, Yang J5, Guglielmi A, et al. Sorafenib or placebo plus TACE with doxorubicin-eluting beads for intermediate stage HCC: the SPACE trial. J Hepatol 2016;64:1090-8.

190. Kudo M, Imanaka K, Chida N, Nakachi K, Tak WY, Takayama T, et al. Phase III study of sorafenib after transarterial chemoembolisation in Japanese and Korean patients with unresectable hepatocellular carcinoma. Eur J Cancer. 2011;47:2117-27.

191. Meyer T, Fox R, Ma YT, Ross PJ, James MW, Sturgess R, et al. Sorafenib in combination with transarterial chemoembolisation in patients with unresectablehepatocellular carcinoma (TACE 2): a randomised placebo-controlled, double-blind, phase 3 trial. Lancet Gastroenterol Hepatol. 2017;2:565-75.

192. Salem R, Lewandowski RJ. Chemoembolization and radioembolization for hepatocellular carcinoma. Clin Gastroenterol Hepatol. 2013;11:604-11.

193. Kulik LM, Carr BI, Mulcahy MF, Lewandowski RJ, Atassi B, Ryu RK, et al. Safety and efficacy of $90 \mathrm{Y}$ radiotherapy for hepatocellular carcinoma with and without portal vein thrombosis. Hepatology. 2008;47:71-81

194. Gil-Alzugaray B, Chopitea A, Inarrairaegui M, Bilbao JI, Rodriguez-Fraile M, Rodriguez J, et al. Prognostic factors and prevention of radioembolization-induced liver disease. Hepatology. 2013;57:1078-87.

195. Kennedy A, Nag S, Salem R, Murthy R, McEwan AJ, Nutting C, et al. Recommendations for radioembolization of hepatic malignancies using yttrium-90 microsphere brachytherapy: a consensus panel report from the radioembolization brachytherapy oncology consortium. Int J Radiat Oncol Biol Phys. 2007; 68:13-23.

196. Salem R, Thurston KG. Radioembolization with 90yttrium microspheres: a stateof-the-art brachytherapy treatment for primary and secondary liver malignancies. Part 2: special topics. J Vasc Intervent Radiol. 2006;17:1425-39.

197. Venkatanarasimha N, Gogna A, Tong KTA, Damodharan K, Chow PKH, Lo RHG, et al. Radioembolisation of hepatocellular carcinoma: a primer. Clin Radiol. 2017;72:1002-13.

198. Mazzaferro V, Sposito C, Bhoori S, Romito R, Chiesa C, Morosi C, et al. Yttrium-90 radioembolization for intermediate-advanced hepatocellular carcinoma: a phase 2 study. Hepatology. 2013;57:1826-37.

199. Salem R, Lewandowski RJ, Mulcahy MF, Riaz A, Ryu RK, Ibrahim S, et al. Radioembolization for hepatocellular carcinoma using Yttrium-90 microspheres: a comprehensive report of long-term outcomes. Gastroenterology. 2010;138:52-64.

200. Hilgard P, Hamami M, Fouly AE, Scherag A, Muller S, Ertle J, et al. Radioembolization with yttrium- 90 glass microspheres in hepatocellular carcinoma: European experience on safety and long-term survival. Hepatology. 2010;52:1741-9.

201. Zhang Y, Li Y, Ji H, Zhao X, Lu H. Transarterial Y90 radioembolization versus chemoembolization for patients with hepatocellular carcinoma: A meta-analysis. Bioscience Trends. 2015;9:289-98.

202. Vilgrain V, Pereira H, Assenat E, Guiu B, Ilonca AD, Pageaux GP, et al. Efficacy and safety of selective internal radiotherapy with yttrium-90 resin microspheres compared with sorafenib in locally advanced and inoperable hepatocellular carcinoma (SARAH): an open-label randomised controlled phase 3 trial. Lancet Oncol. 2017;18:1624-36.

203. Chow PKH, Gandhi M, Tan SB, Khin MW, Khasbazar A, Ong J, et al. SIRveNIB: Selective Internal Radiation Therapy Versus Sorafenib in Asia-Pacific Patients With Hepatocellular Carcinoma. J Clinical Oncol. 2018;36:1913-21.

204. Bolondi L, Burroughs A, Dufour JF, Galle PR, Mazzaferro V, Piscaglia F, et al. Heterogeneity of patients with intermediate (BCLC B) hepatocellular carcinoma: proposal for a subclassification to facilitate treatment decisions. Semin Liver Dis. 2012;32:348-59.

205. Bruix J, da Fonseca LG, Reig M. Insights into the success and failure of systemic therapy for hepatocellular. Nature Reviews Gastroenterol Hepatol 2019. Published online. Doi: https://doi.org/10.1038/s41575-019-0179-x.

206. Raoul JL, Kudo M, Finn RS, Edeline J, Reig M, Galle PR. Systemic therapy for intermediate and advanced hepatocellular carcinoma: sorafenib and beyond. Cancer Treat Rev. 2018;68:16-24.

207. Rocarina D, Majumdar A, Thorburn D, Davidson BR, Tsochatzis E, Gurusamy KS. Management of people with intermediate-stage hepatocellular carcinoma. Cochrane Database Syst Rev 2017.
208. Cuchetti A, Sposito C, Pinna AD, Citterio D, Cescon M, Bongini M, et al. Competing risk analysis on outcome after hepatic resection of hepatocellular carcinoma in cirrhotic patients. World J Gastrenterol. 2017;23:1469-76.

209. Cauchy F, Soubrane O, Belguithi J. Liver resection for HCC: Patients's selection and controversial scenarios. Best Practice Res Clin Gastrenterol. 2014;28:881-96.

210. Yang B, Zheng B, Yang M, Zeng Z, Yanf F, Pu J, et al. Liver resection vesus transarterial chemoembolization for the initial treatment of Barcelona Clinic Liver Cancer stage B hepatocellular carcinoma. Hepatol Int 2018;12:417-28.

211. Koh YX, Tan HL, Lye WK, Kam JH, Chiow AKH, Tan SS, et al. Systematic review of the outcomes of surgical resection for intermediate and advanced Barcelona Clinic Liver Cancer stage hepatocellular carcinoma: A critical appraisal of the evidence. World J Hepatol. 2018;10:433-47.

212. Bell R, Pandanboyana S, CLodge JPA. Primary liver resection for patients with cirrhosis and hepatocellular carcinoma: the role of surgery in BCLC early (A) and intermediate stages (B). Langenbecks Arch Surg. 2017;402:575-83.

213. Van Mierlo KMC, Schaap FG, Dejong CH, Olde Damink SW. Liver resection for cancer: new developments in prediction, prevention and management of postresectional liver failure. J Hepatol. 2016:1217-31.

214. Tustumi F, Ernani L, Coelho FF, Bernardo WM, Junior SS, Kruger JAP, et al. Preoperative strategies to improve resecability for hepatocellular: a systematic review. HPB (Oxford). 2018;20:1109-18.

215. Tabrizian P, Roayaie S, Schwartz ME. Current management of hepatocellular carcinoma. World J Gastroenterol. 2014;20:10223-37.

216. Citterio D, Facciorusso A, Sposito C, Rota R, Bhoori S, Mazzaferro V. Hierarchic Interaction of Factors Associated With Liver Decompensation After Resection for Hepatocellular Carcinoma. JAMA Surg. 2016;151:846-53.

217. Lee HW, Suh KS. Expansion of the criteria for living donor liver transplantation for hepatocellular carcinoma. Curr Opin Organ Transplant. 2016;21:231-7.

218. Viveiros A, Zoller H, Finkenstedt A. Hepatocellular carcinoma: when is liver transplantation oncologically futile? Transl Gastroenterol Hepatol. 2017; $24 ; 2: 63$.

219. Gunsar F. Liver Transplantation for Carcinoma Beyond the Milan Criteria. Exp Clin Transplant. 2017;15(Suppl 2):59-64.

220. Sapisochin G, Goldaracena N, Laurence JM, Dib M, Barbas A, Ghanekar A, et al. The extended Toronto criteria for liver transplantation in patients with hepatocellular carcinoma: A prospective validation study. Hepatology. 2016;64: 2077-88.

221. Hakeem AR, Young RS, Marangoni G, Lodge JP, Prasad KR. Systematic review: the prognostic role of alpha-fetoprotein following liver transplantation for hepatocellular carcinoma. Aliment Pharmacol Ther. 2012;35:987-99.

222. Xu DW, Wan P, Xia Q. Liver transplantation for hepatocellular carcinoma beyond the Milan criteria: A review. World J Gastroenterol. 2016 28;22:3325-34.

223. Giacomoni A, Di Sandro S, Donadon M, Lauterio A, Belli L, Mangoni I, et al. Survival after Liver Transplant: Influence of Progression of Disease and of Restoration of the "Milan" Criteria in Patients with Hepato-cellular Carcinoma undergoing Down-staging Procedures. Hepatogastroenterology. 2015;62:955-61.

224. Finkenstedt A, Vikoler A, Portenkirchner M, Mülleder K, Maglione M, Margreiter $\mathrm{C}$, et al. Excellent post-transplant survival in patients with intermediate stage hepatocellular carcinoma responding to neoadjuvant therapy. Liver Int. 2016;36:688-95

225. Parikh ND, Waljee AK, Singal AG. Downstaging hepatocellular carcinoma: A systematic review and pooled analysis. Liver Transpl. 2015;21:1142-52.

226. Kulik L, Heimbach JK, Zaiem F, Almasri J, Prokop LJ, Wang Z, et al. Therapies for patients with hepatocellular carcinoma awaiting liver transplantation: A systematic review and meta-analysis. Hepatology. 2018;67:381-400.

227. Bryce K, Tsochatzis EA. Downstaging for hepatocellular cancer: harm or benefit ? Transl Gastroenterol Hepatol. 2017;2:106.

228. Olweny CL, Toya T, Katongole-Mbidde E, Mugerwa J, Kyalwazi SK, Cohen H. Treatment of hepatocellular carcinoma with adriamycin. Preliminary communication. Cancer. 1975;36:1250-7.

229. Chlebowski RT, Brzechwa-Adjukiewicz A, Cowden A, Block JB, Tong M, Chan KK. Doxorubicin $(75 \mathrm{mg} / \mathrm{m} 2)$ for hepatocellular carcinoma: clinical and pharmacokinetic results. Cancer Treat Rep. 1984;68:487-91.

230. Lai CL, Wu PC, Chan GC, Lok AS, Lin HJ. Doxorubicin versus no antitumor therapy in inoperable hepatocellular carcinoma. A prospective randomized trial. Cancer. 1988;62:479-83

231. Yeo W, Mok TS, Zee B, Leung TW, Lai PB, Lau WY, et al. A randomized phase III study of doxorubicin versus cisplatin/interferon alpha-2b/doxorubicin/fluorouracil (PIAF) combination chemotherapy for unresectable hepatocellular carcinoma. $\mathrm{J}$ Natl Cancer Inst. 2005;97:1532-8.

232. Qin S, Bai Y, Lim HY, Thongprasert S, Chao Y, Fan J, et al. Randomized, multicenter, open-label study of oxaliplatin plus fluorouracil/leucovorin versus doxorubicin as palliative chemotherapy in patients with advanced hepatocellular carcinoma from Asia. J Clin Oncol. 2013;31:3501-8. 
233. Louafi S, Boige V, Ducreux M, Bonyhay L, Mansourbakht T, de Baere T, et al Gemcitabine plus oxaliplatin (GEMOX) in patients with advanced hepatocellular carcinoma (HCC): results of a phase II study. Cancer. 2007;109:1384-90.

234. Zaanan A, Williet N, Hebbar M, Dabakuyo TS, Fartoux L, Mansourbakht T, et al. Gemcitabine plus oxaliplatin in advanced hepatocellular carcinoma: a large multicenter AGEO study. J Hepatol. 2013;58:81-8.

235. Lee JO, Lee KW, Oh DY, Kim JH, Im SA, Kim TY, et al. Combination chemotherapy with capecitabine and cisplatin for patients with metastatic hepatocellular carcinoma. Ann Oncol. 2009;20:1402-7.

236. Lee J, Park JO, Kim WS, Park SH, Park KW, Choi MS, et al. Phase II study of doxorubicin and cisplatin in patients with metastatic hepatocellular carcinoma. Cancer Chemother Pharmacol. 2004;54:385-90

237. Boucher E, Corbinais S, Brissot P, Boudjema K, Raoul JL. Treatment of hepatocellular carcinoma (HCC) with systemic chemotherapy combining epirubicin, cisplatinum and infusional 5-fluorouracil (ECF regimen). Cancer Chemother Pharmacol. 2002:50:305-8.

238. Porta C, Moroni M, Nastasi G, Arcangeli G. 5-Fluorouracil and d,1-leucovorin calcium are active to treat unresectable hepatocellular carcinoma patients: preliminary results of a phase II study. Oncology. 1995:52:487-91.

239. Tetef M, Doroshow J, Akman S, Coluzzi P, Leong L, Margolin K, et al. 5-Fluorouracil and high-dose calcium leucovorin for hepatocellular carcinoma: a phase II trial. Cancer Invest. 1995;13:460-3.

240. Abdel-Rahman O, Abdel-Wahab M, Shaker M, Abdel-Wahab S, Elbassiony M, Ellithy M. Sorafenib versus capecitabine in the management of advanced hepatocellular carcinoma. Med Oncol. 2013;30:655

241. Boige V, Raoul JL, Pignon JP, Bouché O, Blanc JF, Dahan L, et al; Fédération Francophone de Cancérologie Digestive. Multicentre phase II trial of capecitabine plus oxaliplatin (XELOX) in patients with advanced hepatocellular carcinoma: FFCD 03-03 trial. Br J Cancer. 2007;97:862-7.

242. Lee S, Yoon SH, Park JY, Kim DY, Ahn SH, Han KH, Choi HJ. Sorafenib versus cytotoxic chemotherapy for patients with advanced hepatocellular carcinoma: a retrospective, single-institution study. Invest New Drugs. 2012;30:1150-7.

243. Da Fonseca LG, Marta GN, Braghiroli MIFM, Chagas AL, Carrilho FJ, Hoff PM, Sabbaga J. Safety and efficacy of cytotoxic chemotherapy in hepatocellular carcinoma after first-line treatment with sorafenib. BMC Cancer. 2018; 18:1250.

244. Wörns MA, Galle PR. Sorafenib for the treatment of hepatocellular carcinoma. Hepat Oncol. 2014;1:189-204.

245. Marrero JA, Kudo M, Venook AP, Ye SL, Bronowicki JP, Chen XP, et al. Observational registry of sorafenib use in clinical practice across Child-Pugh subgroups: The GIDEON study. J Hepatol. 2016;65:1140-7.

246. Ganten TM, Stauber RE, Schott E, Malfertheiner P, Buder R, Galle PR, et al. Sorafenib in Patients with Hepatocellular Carcinoma-Results of the Observational INSIGHT Study. Clin Cancer Res. 2017;23:5720-8

247. Parikh ND, Marshall VD, Singal AG, Nathan H, Lok AS, Balkrishnan R, Shahinian V. Survival and cost-effectiveness of sorafenib therapy in advanced hepatocellular carcinoma: An analysis of the SEER-Medicare database. Hepatology. 2017:65:122-33.

248. Finn RS, Zhu AX, Farah W, Almasri J, Zaiem F, Prokop LJ, et al. Therapies for advanced stage hepatocellular carcinoma with macrovascular invasion or metastatic disease: A systematic review and meta-analysis. Hepatology. 2018;67:422-35.

249. Bruix J, Raoul JL, Sherman M, Mazzaferro V, Bolondi L, Craxi A, et al. Efficacy and safety of sorafenib in patients with advanced hepatocellular carcinoma: subanalyses of a phase III trial. J Hepatol. 2012;57:821-9.

250. Bruix J, Cheng AL, Meinhardt G, Nakajima K, De Sanctis Y, Llovet J, et al. Prognostic factors and predictors of sorafenib benefit in patients with hepatocellular carcinoma: Analysis of two phase III studies. J Hepatol. 2017;67:999-1008.

251. Reiss KA, Yu S, Mamtani R, Mehta R, D’Addeo K, Wileyto EP, et al. Starting Dose of Sorafenib for the Treatment of Hepatocellular Carcinoma: A Retrospective, Multi-Institutional Study. J Clin Oncol. 2017;35:3575-81.

252. Bruix J, Takayama T, Mazzaferro V, Chau GY, Yang J, Kudo M, et al. Adjuvant sorafenib for hepatocellular carcinoma after resection or ablation (STORM): a phase 3, randomised, double-blind, placebo-controlled trial. Lancet Oncol. 2015;16:1344-54

253. Mancuso A, Mazzola A, Cabibbo G, Perricone G, Enea M, Galvano A, et al. Survival of patients treated with sorafenib for hepatocellular carcinoma recurrence after liver transplantation: a systematic review and meta-analysis. Dig Liver Dis. 2015;47:324-30.

254. Branco F, Alencar RS, Volt F, Sartori G, Dode A, Kikuchi L, et al. The Impact of Early Dermatologic Events in the Survival of Patients with Hepatocellular Carcinoma Treated with Sorafenib. Ann Hepatol. 2017;16:263-2.
255. Leathers J, Balderramo D, Prieto J, Diehl F, Gonzalez-Ballerga E, Ferreiro MF, et al. Sorafenib for Treatment of Hepatocellular Carcinoma. A Survival Analysis From the South American Liver Research Network. J Clin Gastroenterol. 2019;53:464-9.

256. Bolondi L, Craxi A, Trevisani F, Daniele B, Di Costanzo GG, Fagiuoli S, et al. Refining sorafenib therapy: lessons from clinical practice. Future Oncol. 2015;11:449-65.

257. Bruix J, Qin S, Merle P, Granito A, Huang YH, Bodoky G, et al. Hand-foot skin reaction (HFSR) and overall survival (OS) in the phase 3 RESORCE tria of regorafenib for treatment of hepatocellular carcinoma (HCC) progressing on sorafenib. J Clinical Oncol. 2018:36:412.

258. Zhu AX, Kang YK, Yen CJ, Finn RS, Galle PR, et al. Ramucirumab after sorafenib in patients with advanced hepatocellular carcinoma and increased $\alpha$-fetoprotein concentrations (REACH-2): a randomised, double-blind, placebo-controlled, phase 3 trial. Lancet Oncol. 2019;20:282-96.

259. El-Khoueiry AB, Sangro B, Yau T, Crocenzi TS, Kudo M, et al. Nivolumab in patients with advanced hepatocellular carcinoma (CheckMate 040): an open-label, non-comparative, phase $1 / 2$ dose escalation and expansion trial. Lancet. 2017:389:2492-502.

260. Food and Drug Administration. Sorafenib (Nexavar) prescribing information. 2018 [Internet]. Available from: https://www.accessdata.fda.gov/drugsatfda_docs/ label/2018/021923s020lbl.pdf

261. Food and Drug Administration. Regorafenib (Stivarga) prescribing information 2018 [Internet]. Available from: https://www.accessdata.fda.gov/drugsatfda_docs/ label/2017/203085s007lbl.pdf

262. Ogasawara S, Chiba T, Ooka Y, Kanogawa N, Saito T, Motoyama T, et al. Sorafenib treatment in Child-Pugh A and B patients with advanced hepatocellular carcinoma: safety, efficacy and prognostic factors. Invest New Drugs. 2015:33:729-39.

263. Reig M, Gazzola A, Di Donato R, Bruix J. Systemic treatment. Best Pract Res Clin Gastroenterol. 2014;28:921-35

264. Brose MS, Frenette CT, Keefe SM, Stein SM. Management of sorafenib-related adverse events: a clinician's perspective. Seminars in Oncology. 2014; 41:S1-S16.

265. Ren Z, Zhu K, Kang H, Lu M, Qu Z, Lu L, et al. Randomized controlled tria of the prophylactic effect of urea-based cream on sorafenib-associated hand-foot skin reactions in patients with advanced hepatocellular carcinoma. J Clin Oncol 2015;33:894-900.

266. Lacouture ME, Wu S, Robert C, Atkins MB, Kong HH, Guitart J, et al. Evolving strategies for the management of hand-foot skin reaction associated with the multitargeted kinase inhibitors sorafenib and sunitinib. Oncologist. 2008:13:1001-11.

267. Bracarda S, Ruggeri EM, Monti M, Merlano M, DAngelo A, Ferrau F, et al Early detection, prevention and management of cutaneous adverse events due to sorafenib: Recommendations from the Sorafenib Working Group. Crit Rev Oncol Hematol. 2012;82:378-86.

268. Anderson R, Jatoi A, Robert C, Wood LS, Keating KN, Lacouture ME. Search for evidence-based approaches for the prevention and palliation of hand-foo skin reaction (HFSR) caused by the multikinase inhibitors (MKIs). Oncologist. 2009:14:291-302.

269. Wood LS. Managing the side effects of sorafenib and sunitinib. Comm Oncol. 2006;3:558-62.

270. Abdel-Rahman O, Lamarca A. Development of sorafenib-related side effects in patients diagnosed with advanced hepatocellular carcinoma treated with sorafenibe: a systematic-review and meta-analysis of the impact on survival Expert Rev Gastroenterol Hepatol. 2017;11:75-83.

271. Reig M, Torres F, Rodriguez-Lope C, Forner A, N LL, Rimola J, et al. Early dermatologic adverse events predict better outcome in HCC patients treated with sorafenib. J Hepatol. 2014;61:318-24.

272. Rigo JC, Santos E. Contextualizando os Cuidados Paliativos em Geriatria e Gerontologia. In: Dalacorte RR, Rigo JC, Schneider RH, Schwanke CHA. Cuidados Paliativos em Geriatria e Gerontologia. São Paulo: Atheneu; 2012. p. 3-7.

273. Ferrell BR. Integration of Palliative Care Into Standard Oncology Care: American Society of Clinical Oncology Clinical Practice Guideline Update. J Clin Oncol. 2017:35:96-112.

274. Kumar M, Panda D. Role of supportive care for terminal stage hepatocellular carcinoma. J Clin Exp Hepatol. 2014;4:S130-S139.

275. Bosilkovska, M. Analgesics in Patients with Hepatic Impairment: Pharmacology and Clinical Implications. Drugs. 2012;72:1645-69.

276. Koretz RL, Avenell A, Lipman TO. Nutritional support for liver disease. Cochrane Database Syst Rev. 2012;5:CD008344.

277. Mudumbi SK, Bourgeois CE, Hoppman NA, Smith CH, Verma M, Bakitas MA, et al. Palliative Care and Hospice Interventions in Decompensated Cirrhosis and Hepatocellular Carcinoma: A Rapid Review of Literature. J Palliat Med. 2018;20:1-8

\section{(cc) BY-NC}

